ORNL/ SUB--88-07685CT92/02

DE92 040520

\title{
FE3AI-TYPE IRON ALUMINIDES: AQUEOUS CORROSION PROPERTIES IN A RANGE OF ELECTROLYTES AND SLOW-STRAIN-RATE DUCTILITIES DURING AQUEOUS CORROSION
}

\author{
August, 1992 \\ Research snonsored by the U.S. Department of Energy, \\ Fossil Energy \\ Advanced Research and Technology Development Materials Program \\ Repon Prepared by \\ R.A. Buchanan and J.G. Kim \\ Department of Materials Science and Engineering \\ The University of Tennessee \\ Knoxville, TN 37996-2200 \\ under \\ Suhcontract Number 11B-07685CT92 \\ for \\ OAK RIDGE NATIONAL LABORATORY \\ Oak Ridge, Tennessee 37831 \\ managed by \\ MARTIN MARIETTA ENERGY SYSTEMS, INC. \\ for the \\ U.S. Department of Energy \\ under Contract No. DE-AC05-84OR21400
}




\section{CONTENTS}

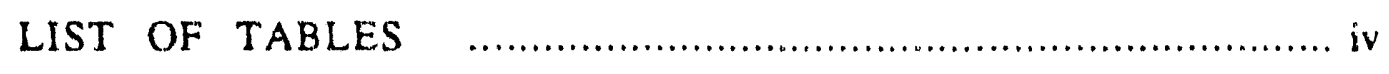

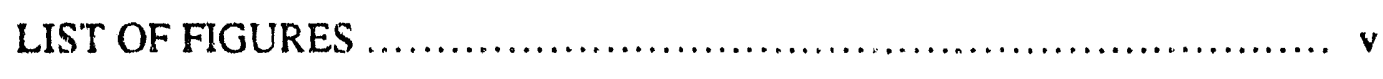

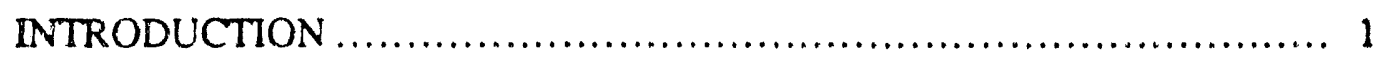

PROCEDURES AND RESULTS .................................... 2

CORROSION CHARACTERIZATIONS UNDER

NON-CREVICE CONDITIONS .................................... 2

CORROSION CHARACTERIZATIONS UNDER

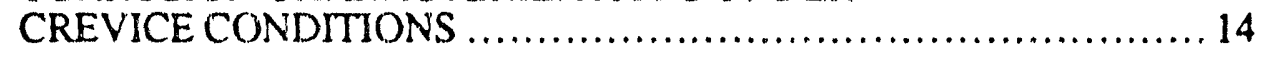

COMPOSITIONAL ANALYSES OF PASSIVE FILMS ..............25

DUCTILITIES UNDER SLOW-STRAIN-RATE

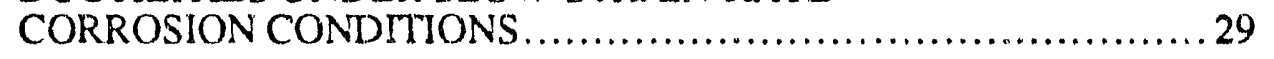

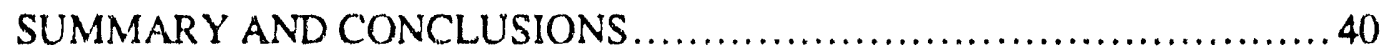

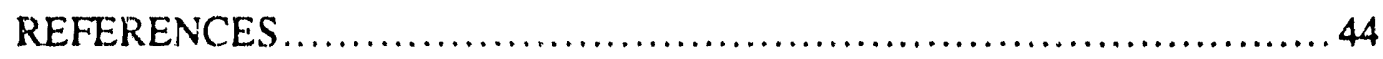

APPENDIX: DISTRIBUTION LIST .................................46 


\section{LIST OF TABLES}

Table 1. Summary of cyclic anodic polarization results .................. 9

Table 2. Electrochemical parameters in the chloride solutions ...............11

Table 3. Results of polarization resistance measurements.................. 12

Table 4. Results of three-week mass-loss immersion tests......................13

Table 5. Electrochemical parameters for non-creviced and creviced conditions in mild acid-chloride solution ( $\mathrm{pH}=4,200 \mathrm{ppm} \mathrm{C.1-}$ ). ...20

Table 6. Three-week immersion test results for creviced specimens in mild acid-chloride solution............................. 22

Table 7. X-ray photoelectron spectroscopy results.............................26

Table 8. Slow-strain-rate $\left(1.2 \times 10^{-6} / \mathrm{s}\right)$ test results......................... 34 


\section{LIST OF FIGURES}

Fig. 1. Schematic experimental cyclic anodic polarization curves ........... 4

Fig. 2... Cyclic anodic polarization results in $1 \mathrm{~N} \mathrm{HCl} \ldots \ldots \ldots \ldots \ldots \ldots \ldots 6$

Fig. 3. Cyclic anodic polarization results in $1 \mathrm{~N} \mathrm{H}_{2} \mathrm{SO}_{4} \ldots \ldots \ldots \ldots \ldots \ldots 6$

Fig. 4. Cyclic anodic polarization results in $1 \mathrm{~N} \mathrm{HNO}_{3} \ldots \ldots \ldots \ldots \ldots \ldots 7$

Fig. 5. Cyclic anodic polarization results in $1 \mathrm{M} \mathrm{NaOH} \ldots \ldots \ldots \ldots \ldots \ldots . . . . . . . .7$

Fig. 6. Cyclic anodic polarization results in mild acid-chloride

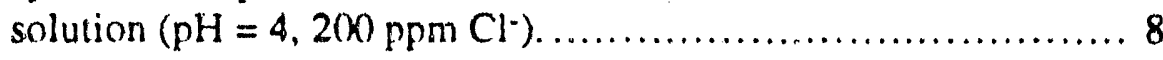

Fig. 7. Cyclic anodic polarization results in $3.5 \mathrm{wt}$. $\% \mathrm{NaCl}$.............. 8

Fig. 8. Cyclic anodic polarization results in synthetic seawater............. 9

Fig. 9. Serrated washer used in the multiple-crevice assembly (a), specimen for immersion testing (b), and specimen for electrochemical polarization testing (c) .......................... is

Fig. 10. Specimen with multiple crevice assembly for electrochemical polarization testing.

Fig. 11. Comparison of creviced and non-creviced cyclic-anodicpolarization behaviors for FA-84 in mild acid-chloride solution $(\mathrm{pH}=4,200) \mathrm{ppm} \mathrm{Cl}^{-}$).

Fig. 12. Comparison of cneviced and nor-creviced cyclic-anodicpolarization behaviors of FAL-Mo in mild acid-chloride solution $\left(\mathrm{pH}=4,200 \mathrm{pmm} \mathrm{Cl}^{-}\right)$.

Fig. 13. Comparison of creviced and non-creviced cyclic-anodicpolarization thehaviors for 304L stainless steel in mild acidchloride solution $\left(\mathrm{pH}=4,2\left(\mathrm{~N}^{\circ}\right) \mathrm{ppm} \mathrm{Cl}^{-}\right)$.

Fig 14. Surfaces of creviced specimens after cyclic-anodicpolarization testing in mild acid-chloride solution:

(a) FA-84, (b) FAL-Mo, and (c) 304L stainless steel

Fig. 15. Surfaces (front and rear) of creviced FA- 84 specimen after three-week immersion in mild acid-chloride solution.

Fig. 16. Surface of creviced 304L stainless steel specimen after threewet: immersion in mild acid-chloride solution.

Fig. 17. Surface of creviced FAL-Mo specimen after three-weekimmersion in mild acid-chloride solution. 
Fig. 18. Concentrations in the passive film and bulk alloy of FA-139 (Fe-28A $1-4 \mathrm{Cr}-1 \mathrm{MO}$ ) after 18 hour immersion in mild acid-chloride solution............................................... 26

Fig. 19. Cyclic anodic polarization behaviors of FA. 72C, FA-139 and FA.129 in mild acid-chloride solution.

Fig. 20. Tensile specimen geometry employed at ORNL, with slowstrain-rate-corrosion fracture locations identified.

Fig. 21. Current slow-strain-rate corrosion test-specimen geometry.

Fig. 22. Slow-strain-rate ductility versus electrochemical potential for FA.84 iron aluminide.

Fig. 23. Slow-strain-rate ductility versus electrochemical potential for FA-129 iron aluminide. 


\title{
EEZAI-TYPE IRON ALUMINIDES:_AOUEOUS CORROSION PROPERTIES IN A RANGE OE ELECTROLYTES AND SLOW-STRAIN-RATE DUCTILITIES DURING AOUEOUS CORROSION *
}

\author{
R.A. Buchanan and J.G. Kim
}

\section{INTRODUCTION}

The $\mathrm{Fe}_{3} \mathrm{Al}$-type iron aluminides have undergone continued development at the $\mathrm{Oak}$ Ridge National Laboratory for enhancement of mechanical and corrosion properties. ${ }^{1-13}$ Improved alloys and thermomechanical processing methods have evolved. The overall furpose of the project herein described was to evaluate the aqueous corrosion properties of the most recent alloy compositions in a wide range of possibiy-aggresive solutions and under several different types of corrosion-test conditions. The work supplements previous aqueous-corrosion studies on iron aluminides hy the present authors. ${ }^{14-16}$

Four stages of this one-year aqueous-corrosion investigation are described. First, the corrosion properties of selected iron aluminides were evaluated by means of electrochemical tests and longer-time immersion tests in a range of acidic, basic and chloride solutions. Theses tests were performed under non-crevice conditions, i.e. the specinens were not designed to contain crevice geometries. Second, the iron-aluminide alloy that proved most resistance to chloride-induced localized corrosion under non-crevice conditions was further evaluated under more-severe crevice conditions by electrochemical and immersion testing. Third, in order to study the relative roles of $\mathrm{Fe}, \mathrm{Al}, \mathrm{Cr}$ and $\mathrm{Mo}$ in

\footnotetext{
* Research sponsored by the U.S. Department of Energy, Fossil Energy AR\&TD Materials Program, DOE/FE AA 1510100 , Work Breakdown Structure Element UT-3.
} 
the formation of passive films, the chemical compositions of passive films were determined by X-ray photoelectron spectroscopy' (XPS). And fourth, in order to study aqueouscorrosion effects on the ductilities of iron aluminides as related to hydrogen embrittlement and/or stress-corrosion cracking, slow-strain-rate corrosion (SSRC) tests were conducted over a range of electrochemical potentials.

\section{PROCEDURES AND RESULTS}

\section{Corrosion Characterizations Under Non-Crevice Conditions}

The principal iron aluminides investigated were FA-129 (Fe-28Al-5Cr-0.2C$0.5 \mathrm{Nb}$, at. \%) and FAL-Mo (Fe-28Al-5Cr-1Mo, at.\%). As comparison or reference materials, the iron aluminide FA-84 (Fe-28Al-2Cr-0.05B, at.\%) and annealed Type $304 \mathrm{~L}$ stainless steel (SS) were also evaluated. The corrosion characteristics of these materials were determined in seven different electrolytes: $1 \mathrm{~N} \mathrm{HCl}, 1 \mathrm{~N} \mathrm{H}_{2} \mathrm{SO}_{4}, 1 \mathrm{~N} \mathrm{HNO}_{3}, 1 \mathrm{M}$ $\mathrm{NaOH}$, a mild acid-chloride solution $\left(\mathrm{pH}=4\left(\mathrm{H}_{2} \mathrm{SO}_{4}\right), 200 \mathrm{ppm} \mathrm{Cl}\right), 3.5$ wt. \% $\mathrm{NaCl}$

$(\mathrm{pH} \approx 7)$, and synthetic seawater (Instant Ocean ${ }^{\mathrm{TM}}$, Aquarium Systems, Mentor, Ohio).

Three types of corrosion evaluations were performed to obtain complementary results. First, electrochemical cyclic anodic polarization measurements were made to determine active or passive hehavior and relative stability within the various solutions. Second, electrochemical polarization resistance measurements were made to obtain corrosion current densities, from which average penetration rates in mils per year (mpy) were calculated by application of Faraday's Law. And third, three-week mass-loss immersion tests were conducted to substantiate the electrochemical results and to evaluate any effects of time. The mass-loss values per unit area per unit time were converted to average penetration rates in mpy for comparison to the polarization resistance results. 
After cutting the specimens to size for the various tests, and after drilling a hole in each immersion-iest specimen, the iron aluminides were heat sreated for $1 \mathrm{~h}$ at $750^{\circ} \mathrm{C}$ in air and then oil quenched. Next, for all materials, the specimens were ground to a 600 -grit (SiC) surface finish. All corrosion tests were conducted at laboratory temperature $\left(-25^{\circ} \mathrm{C}\right)$. In the electrochemical tests, the potential scan rate was $600 \mathrm{~m} \mathrm{~V} / \mathrm{h}$ and the reversing current density for the polarization measurements was $10^{3} \mu \mathrm{A} / \mathrm{cm}^{2}$. Aeration was achieved by sparging vrith oxygen, which also resulted in a stirring action. In the immersion tests, the specimens were supported by glass racks, with each specimen supported vertically by a glass peg through the drilled hole. In the immersion tests, oxygen sparging was not performed; the solutions were in a quiescent condition.

Before presenting the results of the cyclic anodic polarization measurements, a brief review of the typical forms of results and their physical interpretations will be given relative to the schematic curves in Figure 1. The anodic curve of Figure l(a) represents active behavior only, i.e. as the potential is increased, the external anodic current density ( $\left.\mathrm{iex}_{\mathrm{ex}}\right)$ increases monotonically. Since $i_{e x}$ is approximately equal to the true anodic current density (at potentials greater than about $50 \mathrm{mV}$ above the open-circuit freely-corroding potential $\left.\left(\mathrm{E}_{\text {corr }}\right)\right)$, which in turn is directly proportional to the metal corrosion rate, this active behavior indicates that the metal corrosion rate continuously increases with increasing potential. The schematic curve of Figure $1(b)$ indicates that active corrosion is occurring at the froely-corroding potential $\left(E_{c o r r}\right)$, but then as the potential is increased, the metal undergoes passivation to a low passive $(P)$ current density $\left(i_{p}\right)$. At higher potentials, breakdown of the passive film occurs resulting in high current densities. Upon reversal of the scan direction, no hysteresis (no $\mathrm{H}$ ) occurs, which generally means that the metal is not susceptible to iccalized forms of corrosion (pitting and crevice corrosion) in this electrolyte. Thus, Figure $1(b)$ indicates active corrosion $(A)$, followed by passivation $(D)$, followed by breakdown of the passive film with no hysteresis (B (no $H)$ ). These tendencies are 


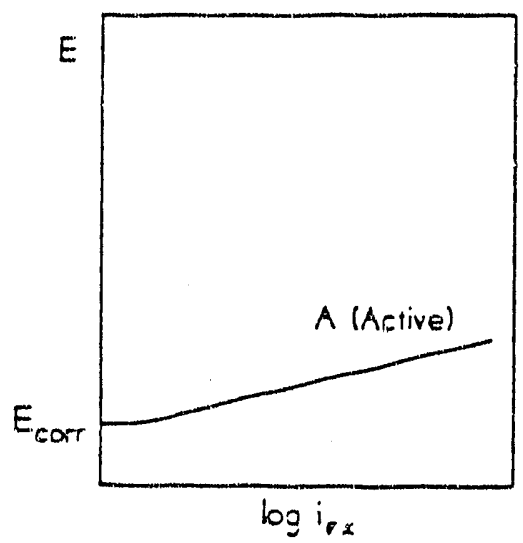

(a)

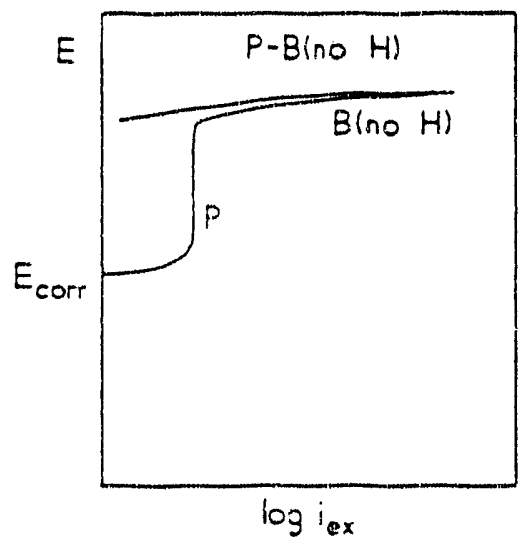

(c)

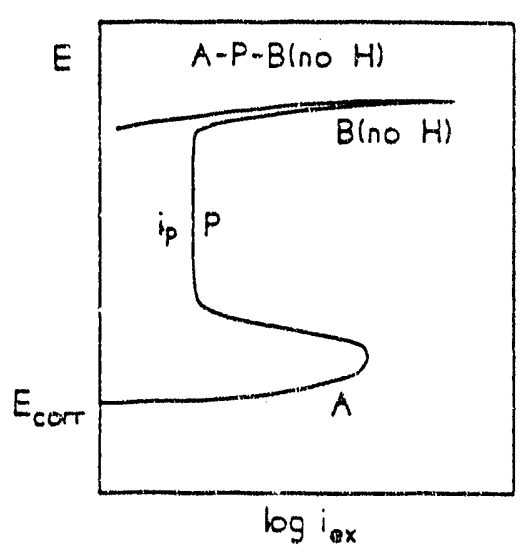

(b)

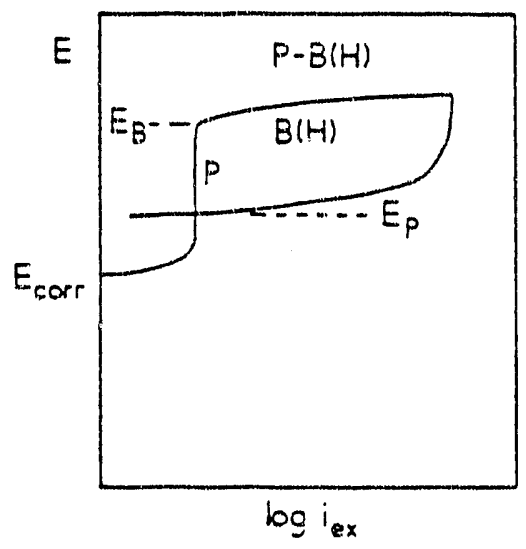

(ci)

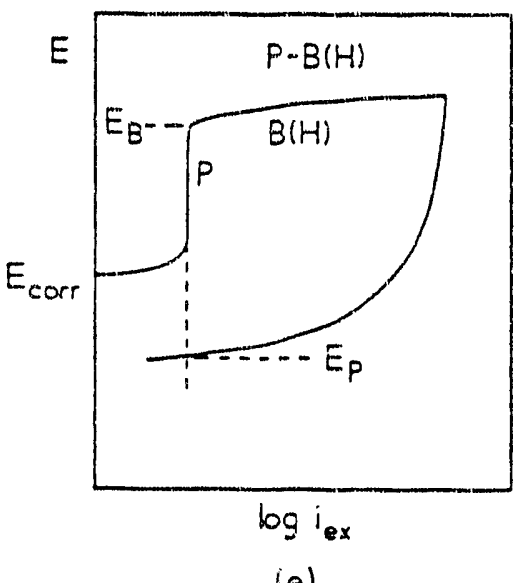

(e)

Fig. 1. Schematic experimental cyclic anodic polarization curves. 
abbreviated as A-P-B (no H). The schematic curve of Figure 1(c) represents, for the most part, ideal behavior. The metal is passivated at the freely corroding potential, and finally undergoes breakdown at a significantly higher potential with no hysteresis, i.e. P-B (no H). The curve of Figure 1(d) indicates passivation at the freely corroding potential, and breakdown at a higher potential with hysteresis during the reverse scan, i.e. P-B (H). The breakdown potential $\left(\mathrm{E}_{\mathrm{B}}\right)$ and the protection potential $\left(\mathrm{E}_{\mathrm{P}}\right)$ are indicated in the figure, where $E_{p}$ is the potential at which the reverse-scan curve intersects the forward-scan curve. The presence of the hysteresis loop indicates susceptibility to localized corrosion in this electrolyte. Although the metal is susceptible to localized corrosion, its relative resistance is proportional to $\left(E_{P}-E_{c o r r}\right)$, i.e. greater resistance is afforded with higher values of $E_{P}$

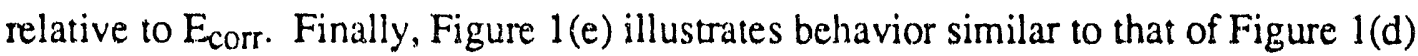
except that $E_{P}$ is below $E_{c o r r}$, indicating less resistance to the onset of localized corrosion.

The results of the cyclic anodic polarization measurements for the four materials (FA-84, FA-129, FAL-Mo and 304L stainless steel (SS)) in the seven different electrolytes are presented in Figures 2-8. Table 1 summarizes these results in terms of the abbrevia:zd notation previously described. In the $1 \mathrm{~N} \mathrm{HCl}$ acid, only active behavior was exhibited by all four materials. In both the $1 \mathrm{~N} \mathrm{H}_{2} \mathrm{SO}_{4}$ and $1 \mathrm{~N} \mathrm{HNO}_{3}$ acids, at the freely-corroding potential $\left(E_{c o r}\right)$, corrosion was taking place in the active state for the three iron aluminides but in the passive state for the $304 \mathrm{~L}$ SS. At higher potentials, the three aluminides underwent passivation. Upon breakdown, or apparent breakdown (oxygen evolution), no hysteresis was exhibited by any of the materials in these acids. In the highly basic $1 \mathrm{M}$ $\mathrm{NaOH}$ solution, all four materials were passivated at $\mathrm{E}_{\mathrm{corr}}$. No hysteresis was exhibited after breakdown (or apparent breakdown). Therefore, although widely differing behaviors were exhibited by the four materials in the three acidic solutions and the one basic solution, no material/electrolyte combination indicated susceptibility to localized pitting/crevice corrosion (i.e. no hysteresis loops were produced). 
Electrolyle: IN Hydrochlor le Acld

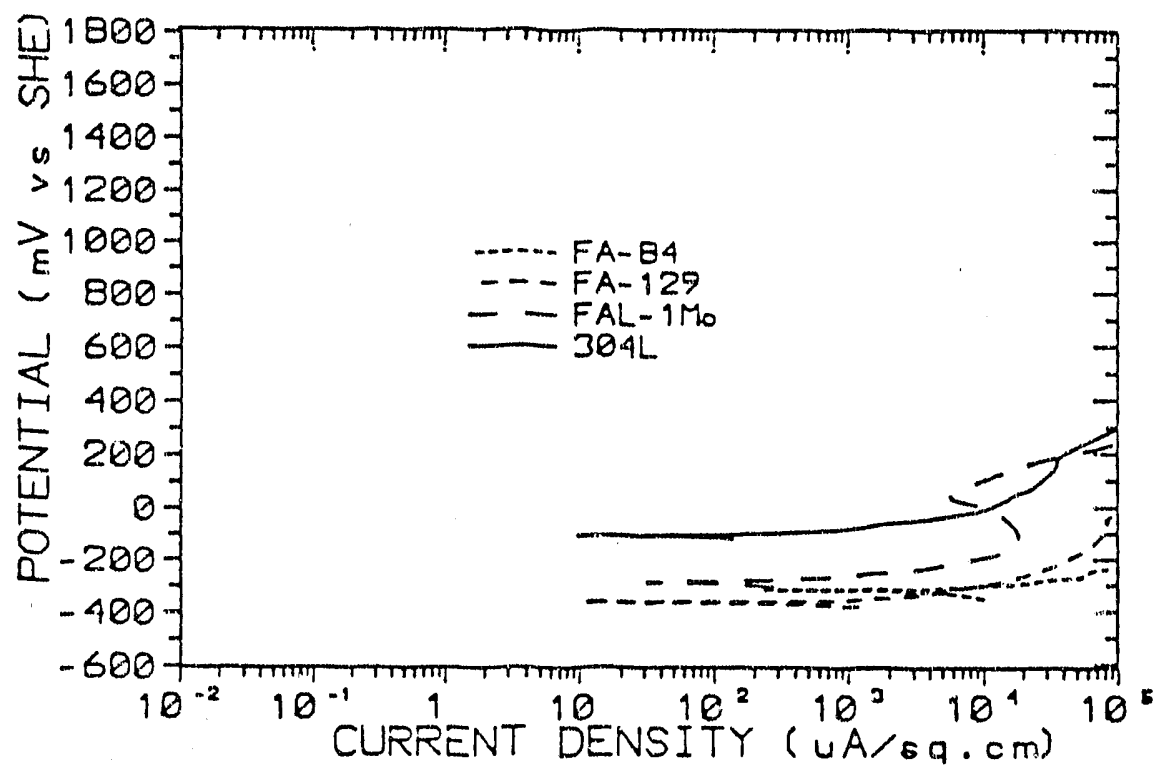

Fig. 2. Cyclic anodic polarization results in $1 \mathrm{~N} \mathrm{HCl}$.

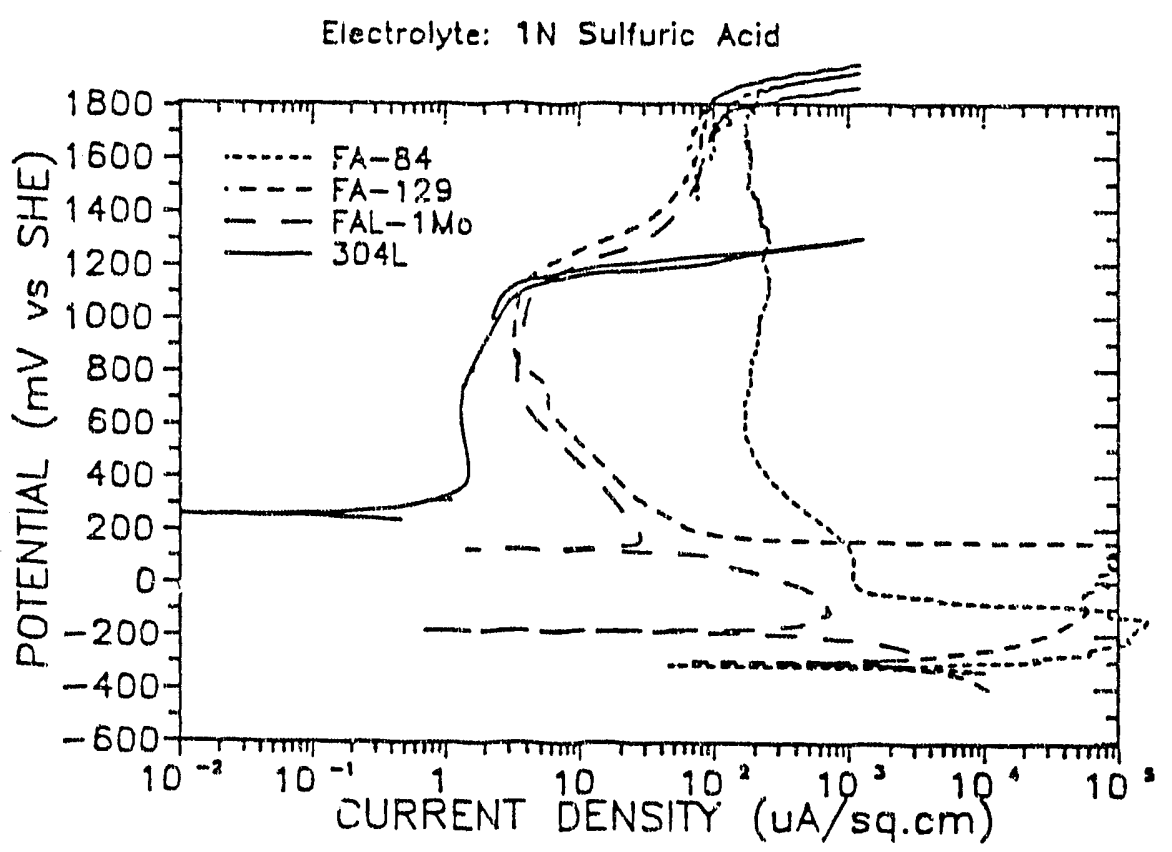

Fig. 3. Cyclic anodic polarization results in $1 \mathrm{~N}_{2} \mathrm{SO}_{4}$. 
Eloelrolylo: IN Nitrle Aeld

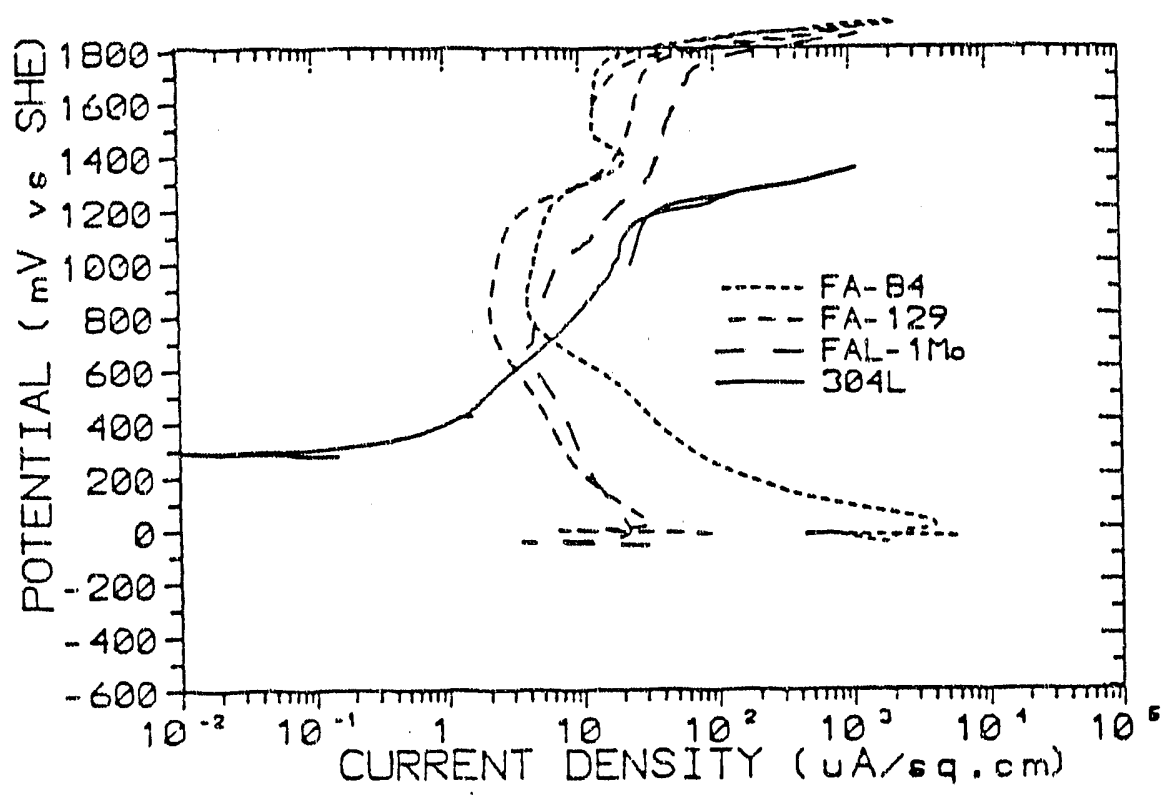

Fig. 4. Cyclic anodic polarization results in $1 \mathrm{~N} \mathrm{HNO}_{3}$.

Electrolyte: IN Sodium Hydroxide

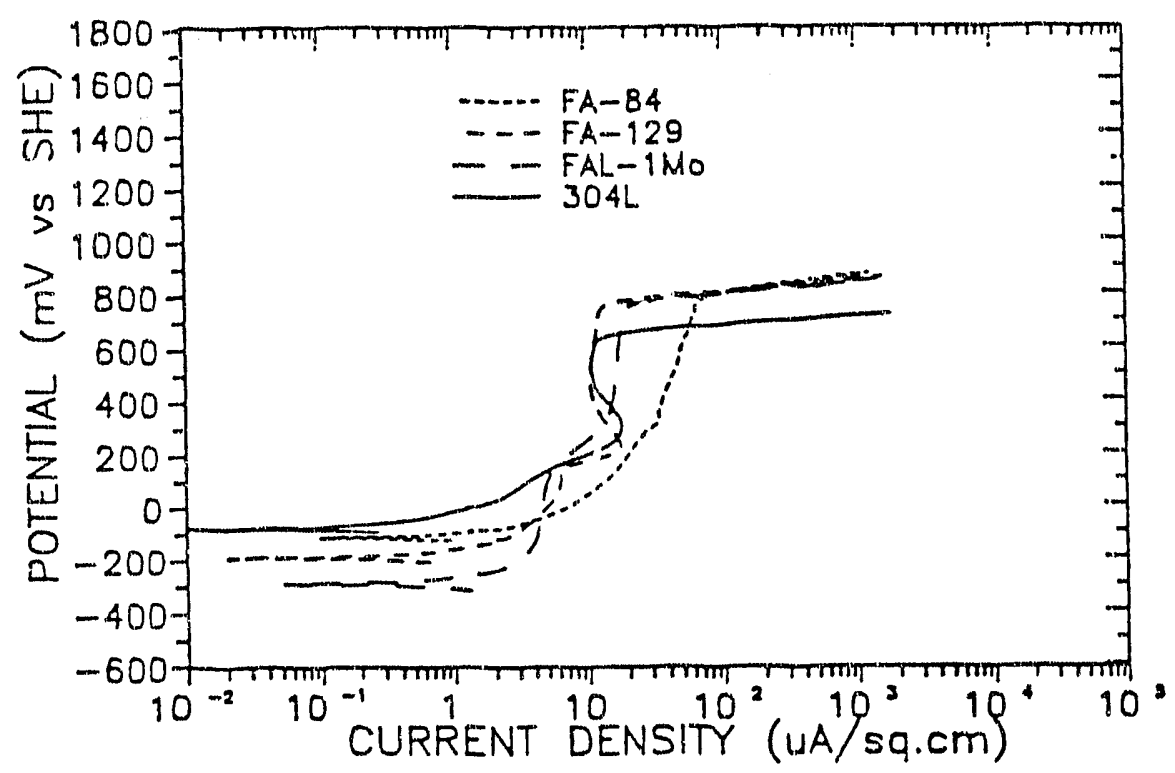

Fig. 5. Cyclic anodic polarization results in $1 \mathrm{M} \mathrm{NaOH}$. 
Elnetrolyte: 200ppon Ehlor (de Ion (pH=4)

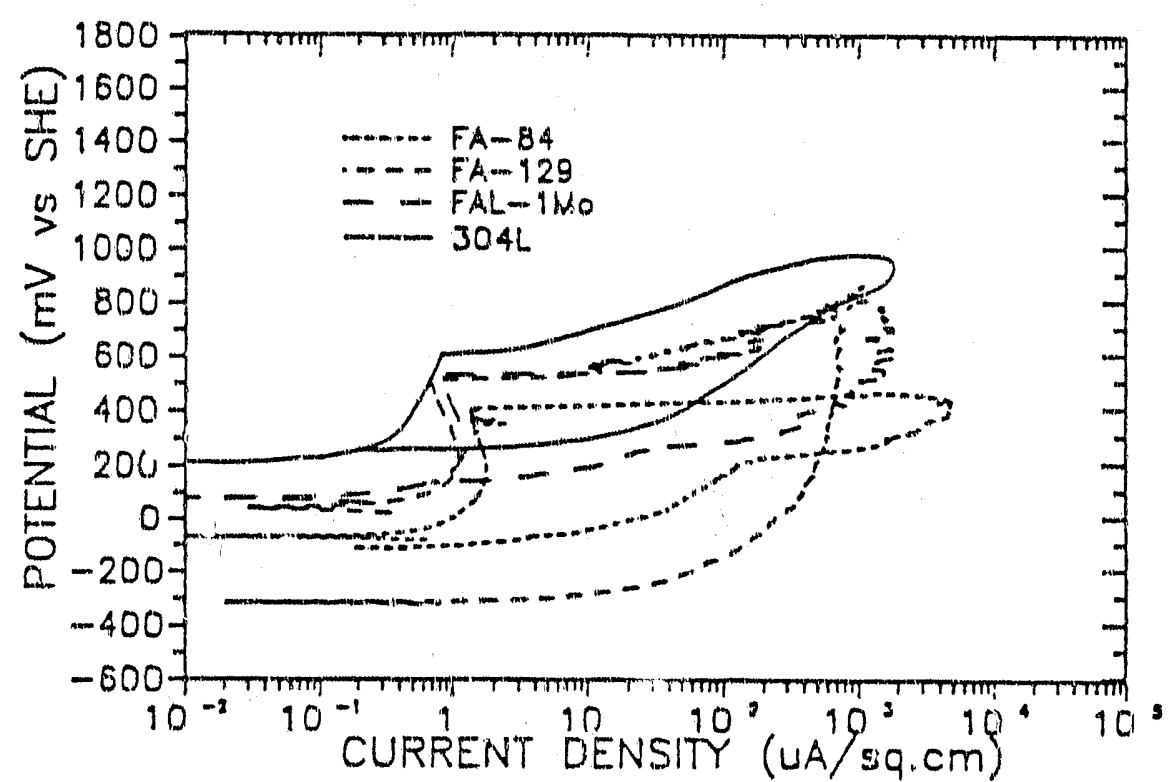

Fig. 6. Cyclic anodic polarization results in mild acid-chloride solution ( $\mathrm{pH}=4,200 \mathrm{ppm} \mathrm{Cl}^{-}$).

Electrolyte: $3.5 x$ Sodiurn Chlaride (pH-7)

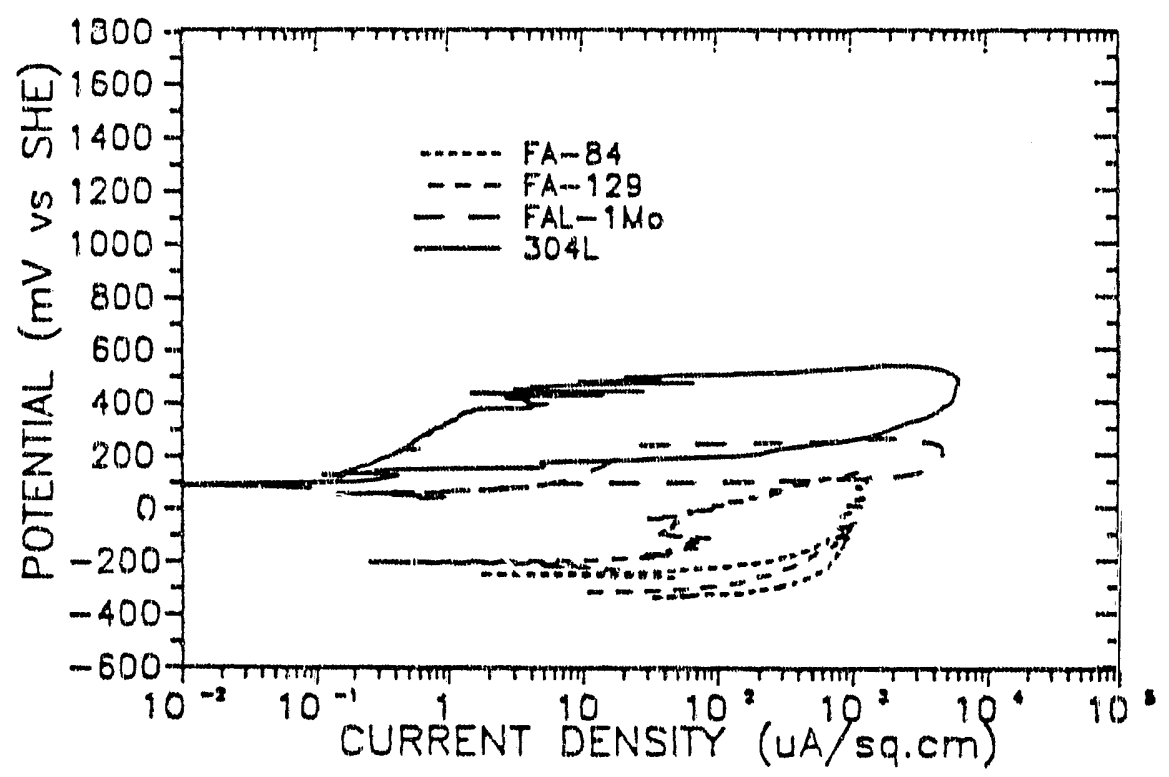

Fig. 7. Cyclic anodic polarization results in $3.5 \mathrm{wt} . \% \mathrm{NaCl}$. 
Electrolyte: Syninetic Seawoter

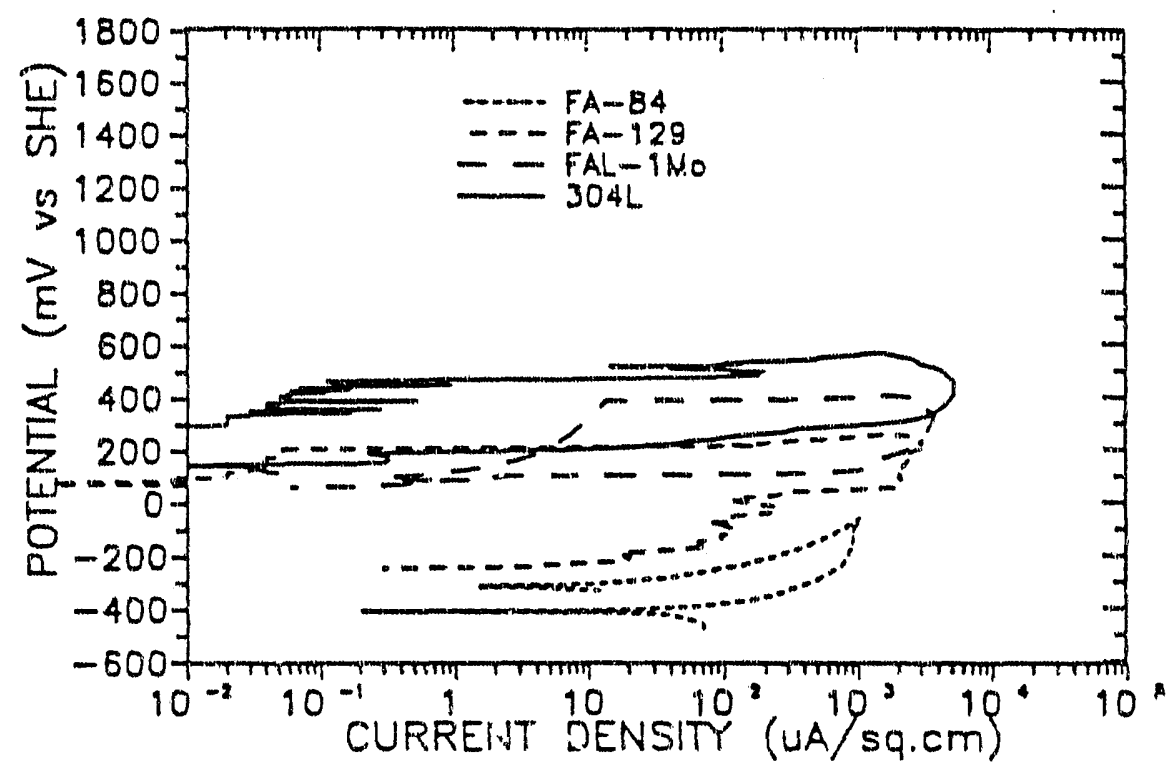

Fig. 8. Cyclic anodic polarization resulu, in synthetic seawater.

Table 1. Summary of cyclic anodic polarization results.

\begin{tabular}{|c|c|c|c|c|c|}
\hline \multicolumn{2}{|r|}{ Solutions } & \multicolumn{4}{|c|}{ Materials } \\
\hline \multirow{4}{*}{ 幽 } & & FA-84 & FA-129 & FAL-Mo & $304 \mathrm{~L}$ SS \\
\hline & $1 \mathrm{~N} \mathrm{HCl}$ & A only & A oniy & A only & A only \\
\hline & $\mathrm{IN} \mathrm{H}_{2} \mathrm{SO}_{4}$ & $A \cdot P \cdot B(n \circ H)$ & $A-P-B($ no $H)$ & $A \cdot P \cdot B(n \circ H)$ & $\mathrm{P}-\mathrm{B}(\mathrm{no} H)$ \\
\hline & $1 \mathrm{~N} \mathrm{HNO}_{3}$ & $A \cdot P \cdot B(n \circ H)$ & A-P.B $(n \circ H)$ & A-P-B $(n \circ H)$ & P.B $(\mathrm{noH})$ \\
\hline ต & $1 \mathrm{M} \mathrm{NaOH}$ & P. $B($ no $H)$ & $\mathrm{P} \cdot \mathrm{B}($ no H $)$ & P-B $(n \circ H)$ & $\mathrm{P}-\mathrm{B}($ no $\mathrm{H})$ \\
\hline \multirow{3}{*}{$\frac{\stackrel{0}{0}}{\frac{\mathscr{E}}{0}}$} & Mild Acid-Chloride & $P \cdot B(H)$ & P-B(H) & P.B(H) & $\mathrm{P}-\mathrm{B}(\mathrm{H})$ \\
\hline & $w t \% \mathrm{NaOH}$ & P-B $(\mathrm{H})$ & P-B $(H)$ & P-B $(\mathrm{H})$ & P-B(H) \\
\hline & Synthetic Seawater & P.B $(\mathrm{H})$ & $\mathrm{P}-\mathrm{B}(\mathrm{H})$ & P-B(H) & P-B $(\mathrm{H})$ \\
\hline
\end{tabular}


In the three chloride-containing solutions (mild acid-chloride, $3.5 \mathrm{wt} . \% \mathrm{NaCl}$ and synthetic seawater), all materials were in the passive stake at $E_{\text {corr }}$, and after breakdown of the passive film, all materials exhibited hysteresis behavior. Therefore, these material/electrolyte combinations exhibited susceptibility to localized corrosion. As previously discussed, a measure of the relative resistance to the onset of localized corrosion is the quantity $\left(E_{P}-E_{c o r r}\right)$, with the resistance increasing as $\left(E_{P}-E_{c o r r}\right)$ increases. This quantity is tabulated in Table 2 for the four materials in the chloride-containing solutions. Based on this electrochemical measurement, FAL-Mo and 304L SS were clearly superior to the other two materials in terms of resistance to chloride-induced localized corrosion. Also, based on these results, a case could be made t'at FAL-Mo was slightly better than $304 \mathrm{~L}$ SS.

The average penetration rates (mpy) at the freely-corroding potential $\left(E_{c o r r}\right)$, as determined by polarization resistance measurements and Faraday's law, are given in Table 3. All four materials produced high corrosion rates in the $1 \mathrm{~N} \mathrm{HCi}$. In the $1 \mathrm{~N} \mathrm{H}_{2} \mathrm{SO}_{4}$, the three iron aluminides produced high corrosion rates corresponding to active corrosion behavior, but the $304 \mathrm{~L}$ SS exhibited a low passive corrosion rate. In the $1 \mathrm{~N} \mathrm{HNO}_{3}$, the FA-84 iron aluminide showed a very high active corrosion rate; however, the FA-129 and FAL-Mo aluminides exhihited much lower active corrosion rates. Based on the polarization behaviors, these latter materials, with a higher $\mathrm{Cr}$ content, were corroding in an active state but very close to a siate of passivation. In the $1 \mathrm{~N} \mathrm{HNO}_{3}$ solution, the $304 \mathrm{~L}$ SS showed a low passive corrosion rate. In the basic $1 \mathrm{M} \mathrm{NaOH}$ solution, all four materials produced low passive corrosion rates. In the three chloride-containing solutions (mild acid-c'duride, $3.5 \mathrm{wt}$. $\% \mathrm{NaCl}$ and synthetic seawater), generally, low passive corrosion rates were exhibited by all materials. Within these solutions, the higher average penetration values (i.e. greater than ahout $1 \mathrm{mpy}$ ) could have been associated with small amounts of localized corrosion during the polari- vtion-resistance measurements. Recall that all of these 
materials exhibited susceptibility to localized corrosion in these solutions by virtue of production of hysteresis loops within their cyclic anodic polarization curves.

Table 2. Electrochemical parameters in the chloride solutions.

Acid-Chloride Solution

\begin{tabular}{|c|c|c|c|c|c|}
\hline Material & $\begin{array}{c}E_{B} \\
m V(S H E)\end{array}$ & $\begin{array}{c}i_{c o r r} \\
\mu A / c m^{2}\end{array}$ & $\begin{array}{c}E_{P} \\
m V(S H E)\end{array}$ & $\begin{array}{c}E_{c o r r} \\
m V(S H E)\end{array}$ & $\begin{array}{c}E_{P}-E_{\text {corr }} \\
m V(S H E)\end{array}$ \\
\hline FA-84 & 420 & 1.04 & -120 & -70 & -50 \\
\hline FA-129 & 500 & 0.44 & -320 & 40 & -360 \\
\hline FAL-Mo & 540 & 0.3 & 140 & 80 & 60 \\
\hline $304 \mathrm{~L}$ & 600 & 0.09 & 240 & 200 & 40 \\
\hline
\end{tabular}

$3.5 \% \mathrm{NaCl}$ Solution

\begin{tabular}{|c|c|c|c|c|c|}
\hline Material & $\begin{array}{c}E_{\mathrm{B}} \\
\mathrm{mV}(\varepsilon H E)\end{array}$ & $\begin{array}{c}\mathrm{i}_{\text {corr }} \\
\mathrm{uA} / \mathrm{cm}^{2}\end{array}$ & $\begin{array}{c}E_{\mathrm{p}} \\
\mathrm{mV}(\mathrm{SHE})\end{array}$ & $\begin{array}{c}E_{\text {corr }} \\
\mathrm{mV}(\mathrm{SHE})\end{array}$ & $\begin{array}{c}E_{\mathrm{p}}-E_{\text {corr }} \\
\mathrm{mV} \text { (SHE) }\end{array}$ \\
\hline FA-84 & -240 & 78.2 & -320 & $-24 \mathrm{C}$ & $-\mathrm{S0}$ \\
\hline FA-129 & -40 & 29.8 .0 .2 & -300 & -200 & -100 \\
\hline FAL-Mo & 250 & 2.3 & 100 & 60 & 40 \\
\hline $304 \mathrm{~L}$ & 490 & 0.15 & 120 & 100 & 20 \\
\hline
\end{tabular}

Synthetic Seawater Solution

\begin{tabular}{|c|c|c|c|c|c|}
\hline Material & $\begin{array}{c}E_{\mathrm{B}} \\
\mathrm{mV}(\mathrm{SHE})\end{array}$ & $\begin{array}{c}\mathrm{i}_{\text {corr }} \\
\mu \mathrm{A} / \mathrm{cm}^{2}\end{array}$ & $\begin{array}{c}\mathrm{E}_{\mathrm{P}} \\
\mathrm{mV}(\mathrm{SHE})\end{array}$ & $\begin{array}{c}\mathrm{E}_{\text {corr }} \\
\mathrm{mV}(\mathrm{SHE})\end{array}$ & $\begin{array}{c}\mathrm{E}_{\mathrm{P}}-\mathrm{E}_{\text {corr }} \\
\mathrm{mV}(\mathrm{SHE})\end{array}$ \\
\hline FA-84 & -300 & 18.27 & -410 & -300 & -110 \\
\hline FA-129 & 200 & 26.73 .0 .02 & -260 & 70 & -330 \\
\hline FAL-Mo & 400 & 1.02 & 50 & 80 & -30 \\
\hline $304 \mathrm{~L}$ & 460 & 0.01 & 140 & 300 & -160 \\
\hline
\end{tabular}


Table 3. Results of polarization resistance measurements.

\begin{tabular}{|c|c|c|c|c|c|}
\hline & \multirow{2}{*}{ Solutions } & \multicolumn{4}{|c|}{ Average Penetration Rates (mpy) } \\
\hline & & & & & \\
\hline \multirow{4}{*}{$\frac{\mathscr{z}}{\tilde{y}}$} & & FA.84 & FA-129 & FAL-Mo & $304 L$ SS \\
\hline & $1 \mathrm{~N} \mathrm{HCl}$ & 6,220 & 740 & 200 & 140 \\
\hline & $1 \mathrm{~N} \mathrm{H}_{2} \mathrm{SO}_{4}$ & 5,800 & 1,040 & 1,770 & 0.2 \\
\hline & $1 \mathrm{NHNO}_{3}$ & 2,240 & 50 & 20 & 0.1 \\
\hline$\underset{\tilde{m}}{\mathscr{\varpi}}$ & $1 \mathrm{M} \mathrm{NaOH}$ & 0.6 & 0.3 & 0.8 & 0.1 \\
\hline \multirow{3}{*}{$\frac{\frac{\mathscr{d}}{2}}{\frac{0}{5}}$} & Mild Acid-Chloride & 0.4 & 0.2 & 0.1 & 0.04 \\
\hline & 3.5 wt $\% \mathrm{NaCl}$ & 33 & 6.7 & 1.0 & 0.06 \\
\hline & Syninetic Seawater & 7.7 & 6.0 & 0.5 & 0.007 \\
\hline
\end{tabular}

The results of the three-week mass-loss immersion tests are presented in Table 4. These results are generally consistent with the polarization-resistance corrosion rates of Table 3. As shown in Table 4, the immersion tests indicated high corrosion rates for the iron aluminides in the $1 \mathrm{~N} \mathrm{HCl}$ and $1 \mathrm{~N} \mathrm{H}_{2} \mathrm{SO}_{4}$ acids. The corrosion rate for the $304 \mathrm{~L}$ SS was much lower than the aluminides in both of these acids, with a very low corrosion rate (passivation) being indicated in the $1 \mathrm{~N} \mathrm{H}_{2} \mathrm{SO}_{4}$. In the $1 \mathrm{~N} \mathrm{HNO}_{3}$, a very high corrosion rate was exhibited for FA-84, much lower comosion rates for FA-129 and FAL-Mo (on the verge of passivation), and an extremely low corrosion rate for the 304L SS (passivation). In the highly-basic $1 \mathrm{M} \mathrm{NaOH}$, very low corrosion rates were produced by all four materiais (passivation). 
Table 4. Results of three-week mass-loss immersion tests.

\begin{tabular}{|c|c|c|c|c|c|}
\hline & \multirow{2}{*}{ Solutions } & \multicolumn{4}{|c|}{ Average Penetration Rates (mpy) } \\
\hline & & & & & \\
\hline \multirow{4}{*}{ 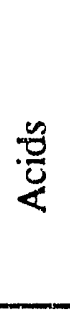 } & & FA-84 & FA-129 & FAL-Mo & 304L SS \\
\hline & $1 \mathrm{~N} \mathrm{HCl}$ & $>8,0201$ & $>3,1502$ & $>6373$ & 6.5 \\
\hline & $1 \mathrm{~N} \mathrm{H}_{2} \mathrm{SO}_{4}$ & $>3,7504$ & $>1,3205$ & $>7486$ & $<0.1$ \\
\hline & $1 \mathrm{NHNO}_{3}$ & $>6,2007$ & 0.25 & 7.0 & $<0.1$ \\
\hline$\underset{\mathscr{E}}{\mathscr{E}}$ & $1 \mathrm{M} \mathrm{NaOH}$ & 0.1 & 0.1 & 0.8 & $<0.1$ \\
\hline \multirow{3}{*}{ 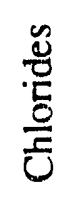 } & Mild Acid-Chloride & $2.3 *$ & $1.6^{*}$ & 0.9 & $<0.1$ \\
\hline & $3.5 \mathrm{wt} \% \mathrm{NaCl}$ & $2.7^{*}$ & $1.8 *$ & 1.6 & $<0.1$ \\
\hline & Synthetic Seawater & $1.0^{*}$ & $1.0^{*}$ & 0.9 & $<0.1$ \\
\hline
\end{tabular}

Total dissolution within--1(12h), 2(36h), 3(192h), 4(24h), 5(72h), 6(213h), 7(12h).

* Localized corrosion initiated w'ithin $24 \mathrm{~h}$.

With regard to the chloride-containing solutions, as shown in Table 4, the mass-loss immersion results indicated low average corrosion rates for all of the materials. However, localized corrosion was observed to initiate for many of the material/electrolyte combinations over the three-week time period. Specifically, in all three chloride solutions, localized corrosion initiated on the FA- 84 and FA-129 iron aluminides within 24 hours. Only the FAL-Mo iron aluminide and 304L SS remained completely passive (no localized corrosion) over the three-week time period in all three chloride solutions. 


\section{Corrosion Characterizations Under Crevice Conditions}

Since the FAL-Mo iron aluminide remained completely passive (no localized corrosion) during the three-week immersion tests in the chloride solutions under noncrevice conditions, as reported in the previous section, it was decided to further evaluate this material under more-severe localized-corrosion conditions. Specifically, specimens were designed to contain crevice geometries; then under these crevice-corrosion conditions, cyclic anodic polarizations tests and three-week immersion tests were conducted in the mild acid-chloride solution ( $\mathrm{pH}=4\left(\mathrm{H}_{2} \mathrm{SO}_{4}\right)$ and $200 \mathrm{ppm} \mathrm{Cl}^{-}(\mathrm{NaCl})$ ). As reference materials, FA-84 and 304L SS were also evaluated in the crevice condition. Except for the introduction of the crevice geometry, all test procedures were exactly the same as described in the previous section of this report.

To form the crevice geometry, a multiple crevice assembly was employed, as indicated in Figures 9 and 10. The assembly consisted of two acetal-resin serrated washers clamped to either side of the specimen hy means of a stainless-steel bolt/nut arrangement (Figure 10). To eliminate galvanic effects, the stainless-steel bolt was not allowed to touch the specimen at the drilled-hole location. The assembly was tightened to a torque of 1.13 $\mathrm{m} \cdot \mathrm{N}$ (10 in. $\mathrm{lbf}$ ). Each serrated washer provided 30 plateau-contact sites; thus the assembly provided 60 crevice sites on each specimen. 


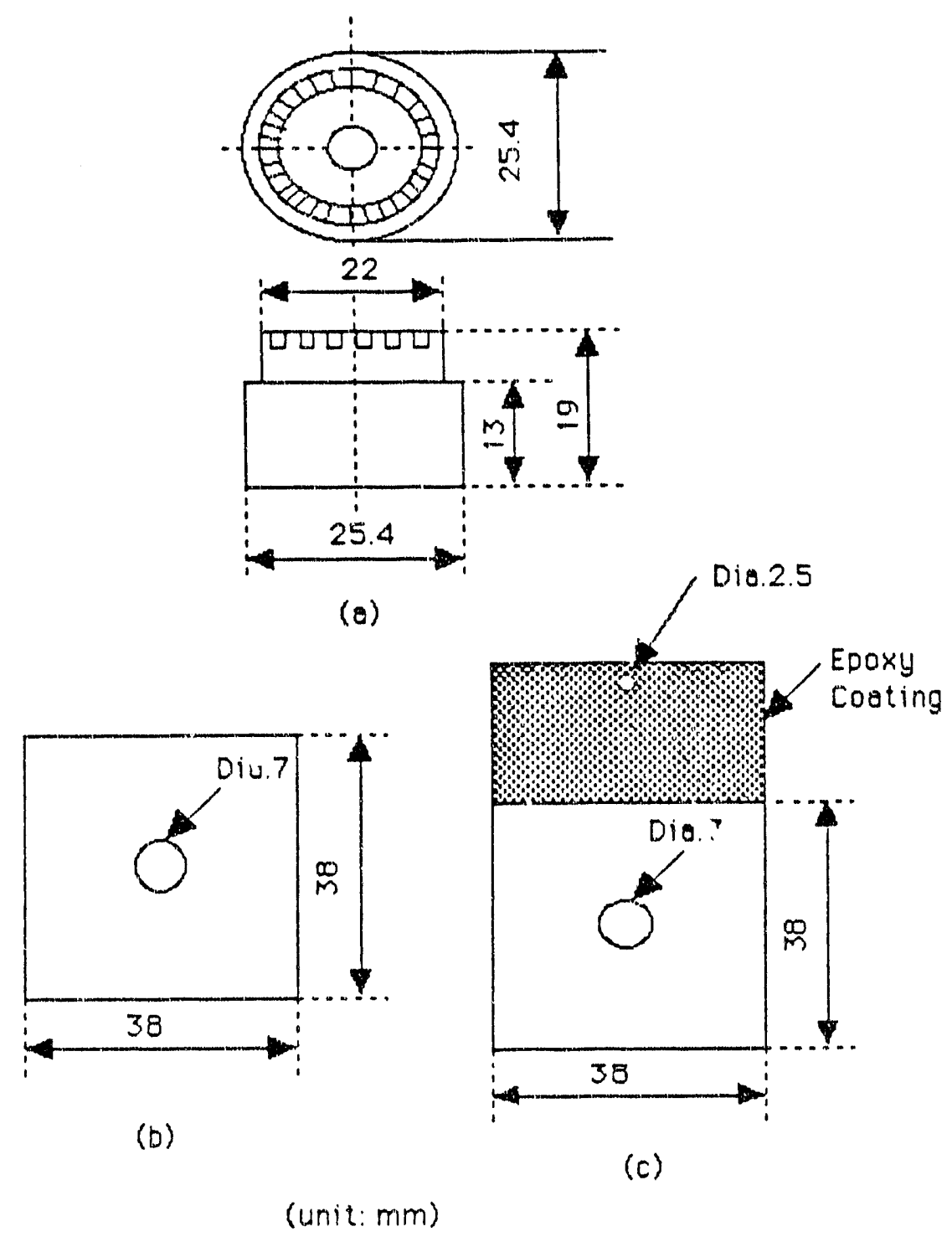

Fig. 9. Serrated washer used in the multiple-crevice assembly (a), specimen for immersion testing (b), and specimen for electrochemical polarization testing (c). 


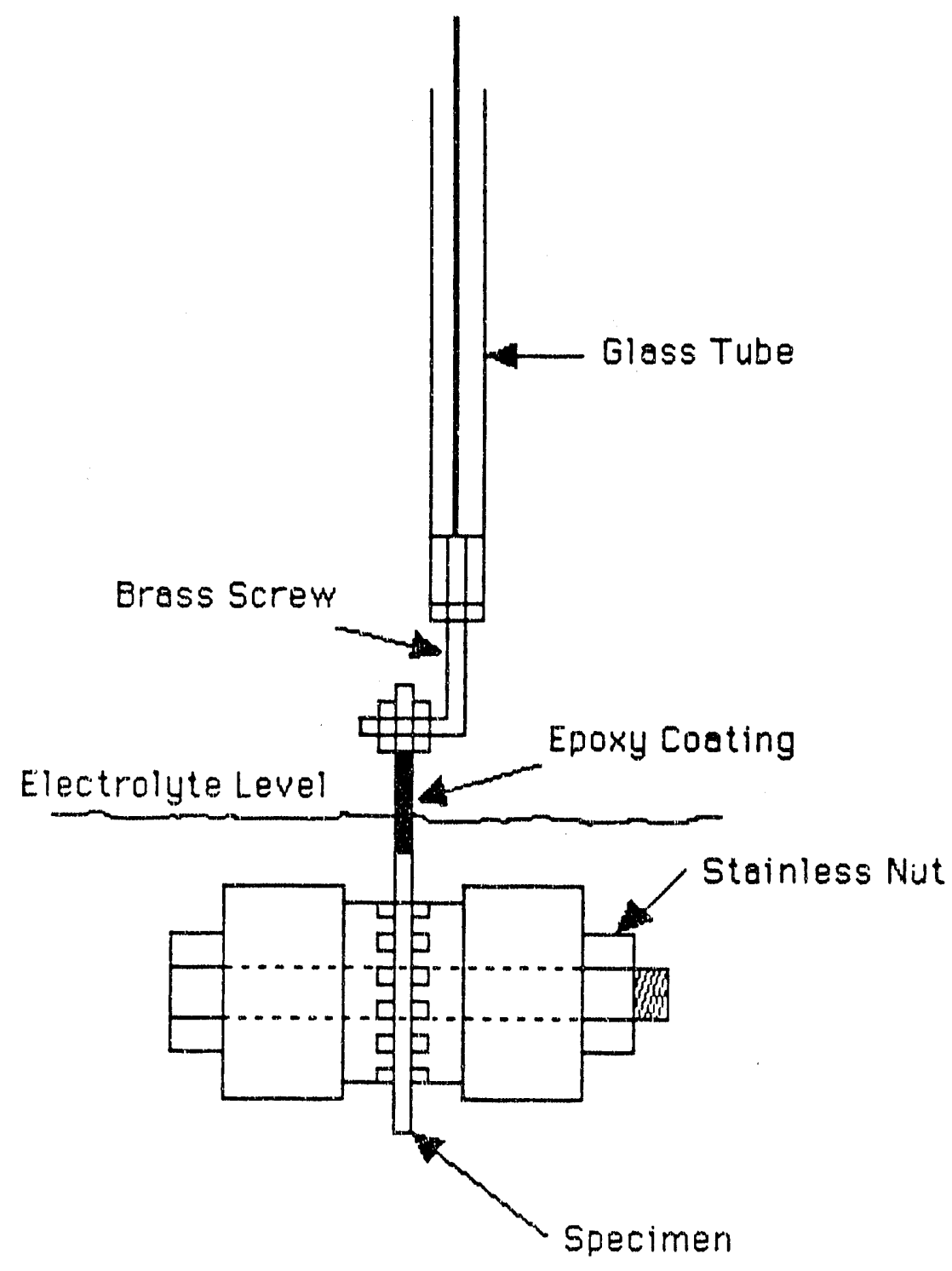

Fig. 10. Specimen with multiple crevice assembly for electrochemical polarization testing. 
Using the crevice arrangement shown in Figure 10, the cyclic anodic polarization behaviors of FA-84, FAL-Mo and 304L SS were evaluated in the mild acid-chloride solution. The results are presented in Figures 11,12 and 13. In each of these figures, for comparison, the previously-reported polarization behavior in the non crevice condition is also shown. With reference to Figure 11 for FA-84, it is seen that the crevice condition produced major changes in the polarization behavior. The crevice condition significantly increased the passive current density $\left(i_{p}\right)$ and decreased the protection potential $\left(\mathrm{E}_{\mathrm{p}}\right)$-- both effects being detrimental to corrosion behavior. With reference to Figure 12 for FAL-Mo, it is seen that the crevice condition shifted the corrosion potential $\left(\mathrm{E}_{\mathrm{cor}}\right)$, the breakdown potential $\left(\mathrm{E}_{\mathrm{B}}\right)$, and the protection potential $\left(\mathrm{E}_{\mathrm{P}}\right)$ all to somewhat lower values, but the form of the cyclic polarization curve and the relative differences between the aforementioned potentials did not change appreciably. Hence, this result indicated that the crevice condition did not cause major changes in the corrosion behavior of FAL-Mo under these polatizationtest conditions. With reference to Figure 13 for 304 L SS, it is seen that the crevice condition produced little change in the corrosion behavior under these polarization-test conditions.

In Table 5, the $E_{B}, E_{p}, E_{c o r r}$ and $\left(E_{p}-E_{c o r r}\right)$ values for the three materials in the noncrevice and crevice conditions are tabulated based on the cyclic polarization curves of Figures 11-13. As discussed in the prior section of this report, the quantity ( $\left.E_{p}-E_{c o r r}\right)$ is most important with regard to localized corrosion. As $\left(E_{p}-E_{c o r r}\right)$ increases, the resistance to localized corrosion increases. It is seen in Table 5 that for the non-crevice condition, the $\left(\mathrm{E}_{\mathrm{p}}-\mathrm{E}_{\mathrm{corr}}\right)$ values for FA-84, 304L SS and FAL-Mo were $-45,+40$ and $+59 \mathrm{mV}$, respectively, indicating progressively increasing resistance to localized corrosion. For the crevice condition, the $\left(\mathrm{E}_{\mathrm{p}}-\mathrm{E}_{\mathrm{corr}}\right)$ values for FA-84, 304L SS and FAL-Mo were $-309,0$ and $+15 \mathrm{mV}$, respectively, again indicating progressively increasing resistance to localized corrosion. For the crevice condition, the relative values of $\left(E_{p}-E_{c o r r}\right)$ for the 
three materials indicated poor resistance FA -84 , but much better and generally comparable resistances for $304 \mathrm{~L}$ and FAL-Mo.

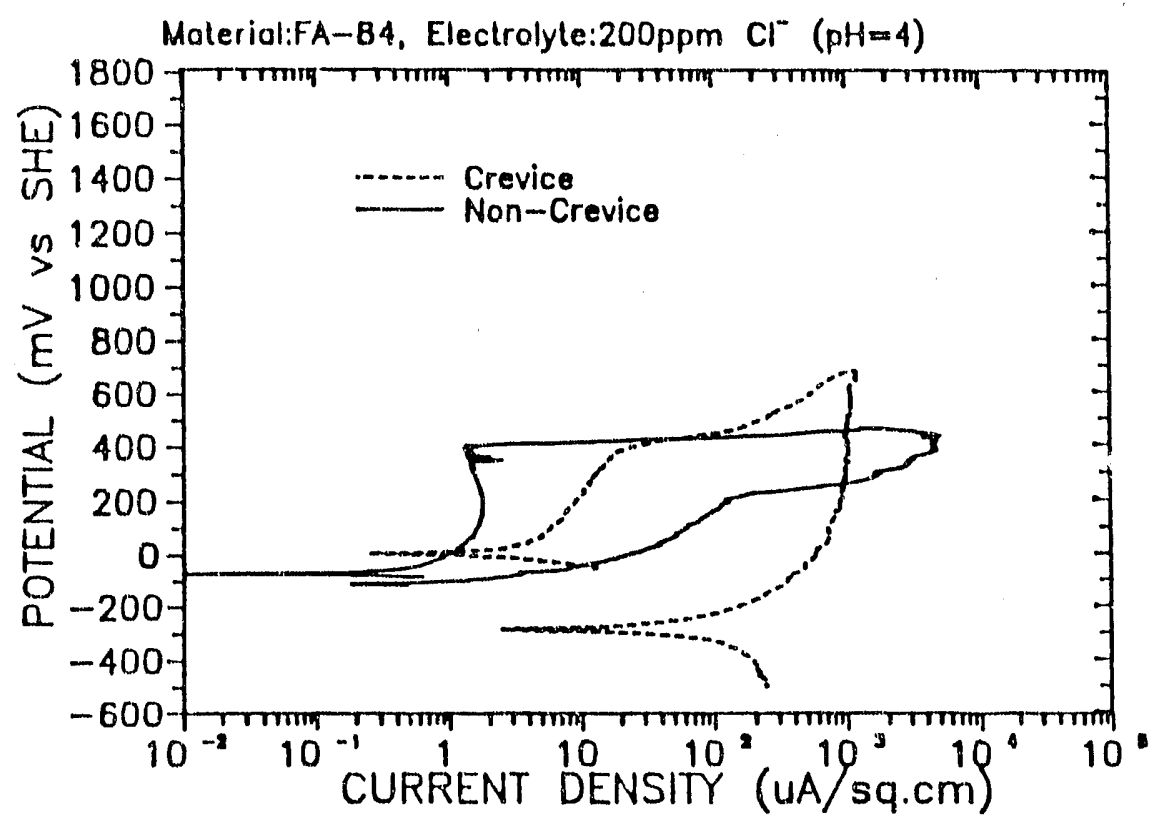

Fig. 11. Comparison of creviced and non-creviced cyclic-anodicpolarization behaviors for FA- 84 in mild acid-chloride solution ( $\mathrm{pH}=4,200 \mathrm{ppm}^{-}$). 


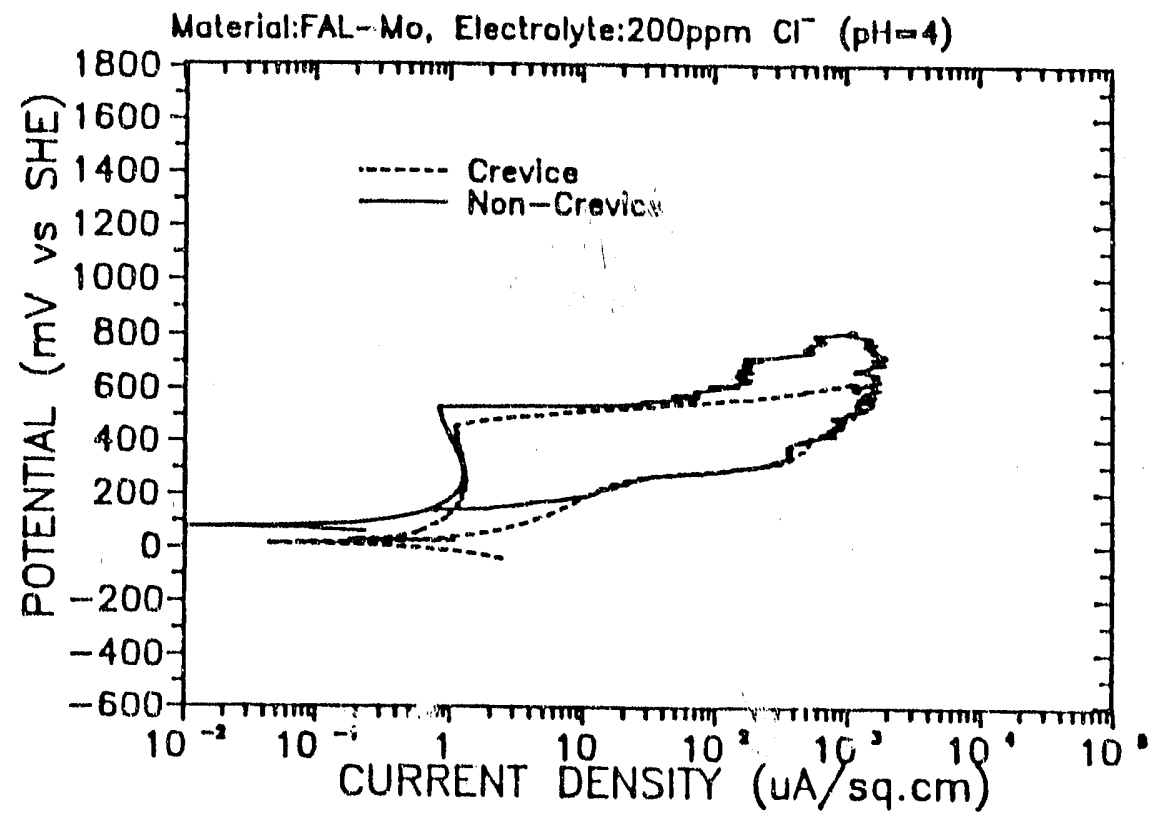

Fig. 12. Comparison of creviced and non-creviced cyclic-anodicpolarizat on behaviors of FAL-Mo in mild acid-chloride solution ( $\mathrm{pH}=4,200 \mathrm{ppm} \mathrm{C1}^{-}$).

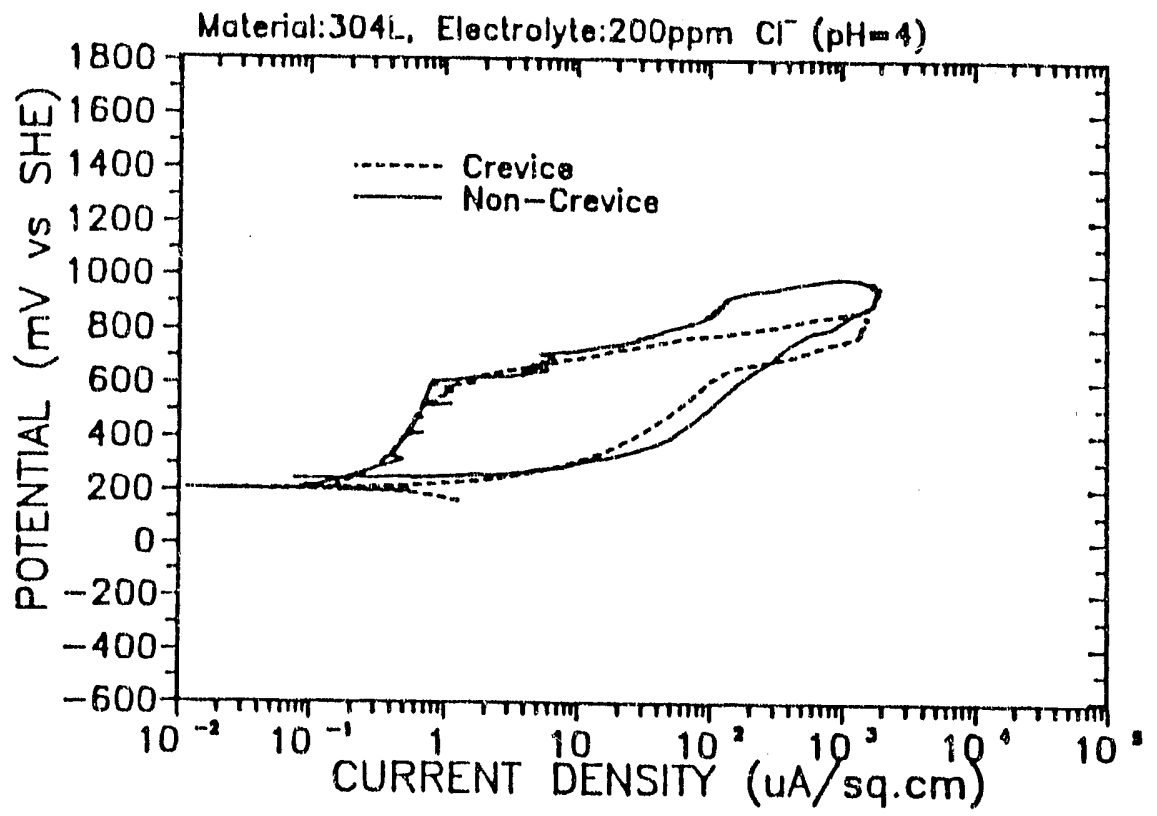

Fig. 13. Comparison of creviced and non-creviced cyclic-anodicpolarization behaviors for 304L stainless steel in mild acidchloride solution $\left(\mathrm{pH}=4,200 \mathrm{ppm} \mathrm{Cl}^{-}\right)$. 
Table 5. Electrochemical parameters for non-creviced and creviced conditions in mild acid-chloride solution ( $\left.\mathrm{pH}=4,200 \mathrm{ppm} \mathrm{C1}^{-}\right)$.

\begin{tabular}{|c|c|c|c|c|}
\hline \multirow[b]{2}{*}{ Material } & \multicolumn{4}{|c|}{ Non-Crevice/Crevice } \\
\hline & $\begin{array}{c}\mathrm{E}_{\mathrm{B}} \\
(\mathrm{mV} \text { vs } \mathrm{SHE})\end{array}$ & $\begin{array}{c}\text { EP } \\
(\mathrm{mV} \text { vs } \mathrm{SHE})\end{array}$ & $\begin{array}{c}E_{\text {corr }} \\
(\mathrm{mV} \text { vs } S H E)\end{array}$ & $\begin{array}{c}E_{p}-E_{\text {corr }} \\
(m V)\end{array}$ \\
\hline FA- 84 & $420 / 420$ & $-115 /-289$ & $-70 / 20$ & $-45 /-309$ \\
\hline 304L SS & $620 / 600$ & $240 / 214$ & $200 / 214$ & $40 / 0$ \\
\hline FAL-Mo & $540 / 460$ & $139 / 30$ & $80 / 15$ & $59 / 15$ \\
\hline
\end{tabular}

Photographs of the surfaces of the FA-84, FAL-Mo and 304L SS specimens after cyclic-anodic polarization testing are shown in Figure 14. It is emphasized here that the polarization testing per se forced the initiation of localized corrosion for all three materials. For FA-84, the polarization test produced both crevice and pitting comosion. However, for FAL-Mo and 304L SS, the polarization tests produced only crevice corrosion. 


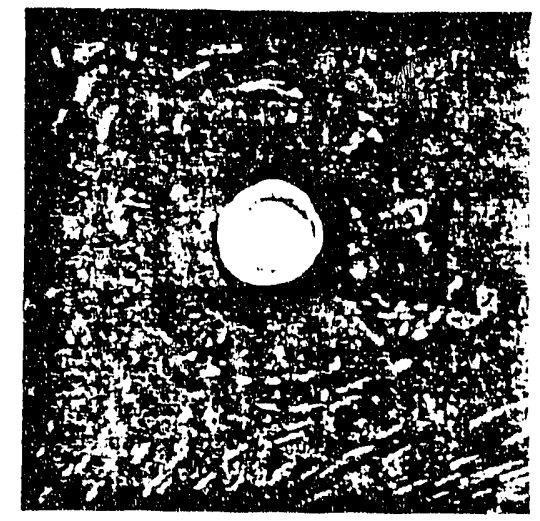

a

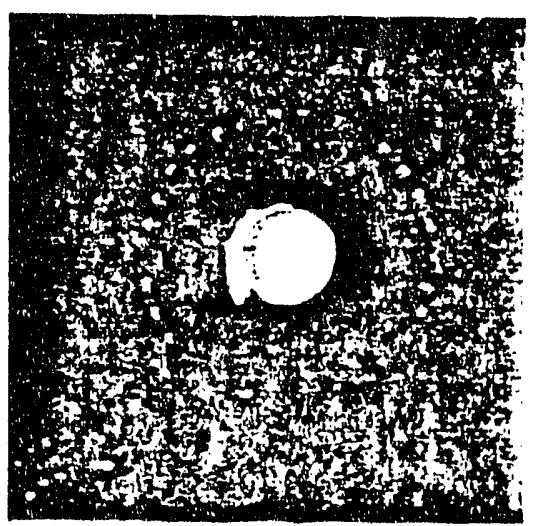

b

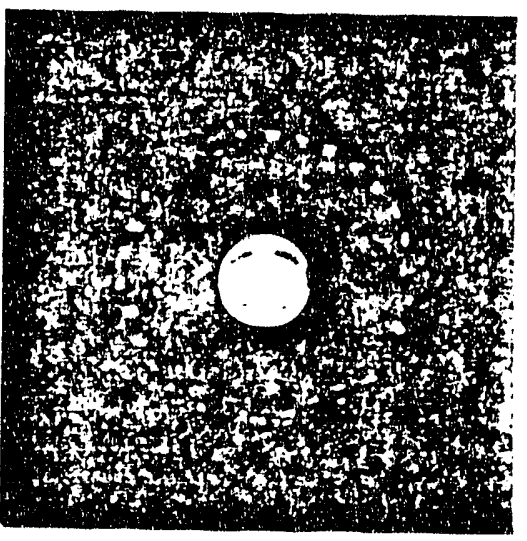

c

Fig. 14. Surfaces of creviced specimens after cyclic-anodicpolarization testing in mild acid-chloride solution:

(a) FA-84, (b) FAL-Mo, and (c) 304L stainless steel 
Following the cyclic anodic polarization testing under crevice conditions, three-week immersion tests were conducted in the mild acid-chloride solution under crevice conditions. After the three-week exposures, the crevice-forming washers were removed and the specimen surfaces were axamined for evidence of localized corrosion. Recall that the multiple crevice assembly produced 60 sites for possible crevice corrosion on each specimen. During examination of each specimen, the number and percentage of sites that actually underwent crevice corrosion were noted and the maximurn depths of corrosive attack were measured. The results are given in Table 6 . It is seen that crevice corrosion initiated at 52 of the 60 sites for FA-84, at one of the 60 sites for 304L, SS and at none of the sites for FAL-Mo. The maximum depths of attack was $6 \mu \mathrm{m}$ for FA-84 and $4 \mu \mathrm{m}$ for 304L SS. Photographs of the specimen surfaces for FA-84, 304L SS and FAL-Mo are shown in Figures 15, 16, and 17, respectively. These immersion-test results in the mild acid-chloride solution under crevice conditions were consistent with the pnedictions derived from analyses of the cyclic polarizations hehavior, i.e. that the $304 \mathrm{~L}$ and FAL-Mo materials should have much higher resistances to localized corrosion relative to FA-84, and that the resistances of $304 \mathrm{~L}$ SS and FAL-Mo should be generally comparable (with a slight advantage to FAL-Mo). In view of these very promising results for the FAL-Mo iron aluminide, additional crevice-corrosion tests are now being conducted in a much-higher chloride-containing solution, 3.5 wt. $\% \mathrm{NaCl}$.

Table 6. Three-week immersion test results for creviced specimens in mild acid-chloride solution.

\begin{tabular}{|c|c|c|c|}
\hline Material & $\begin{array}{c}\text { No. of Crevice Sites } \\
\text { Altacked }(60 \mathrm{max})\end{array}$ & $\begin{array}{c}\text { Percentage of Sites } \\
\text { Attacked }\end{array}$ & $\begin{array}{c}\text { Max. Depth of } \\
\text { Attack }(\mu \mathrm{m})\end{array}$ \\
\hline FA.84 & 52 & 87 & 6 \\
\hline $3(\mathrm{ML}$ SS & 1 & 2 & 4 \\
\hline FAL-MO & 0 & 0 & 0 \\
\hline
\end{tabular}



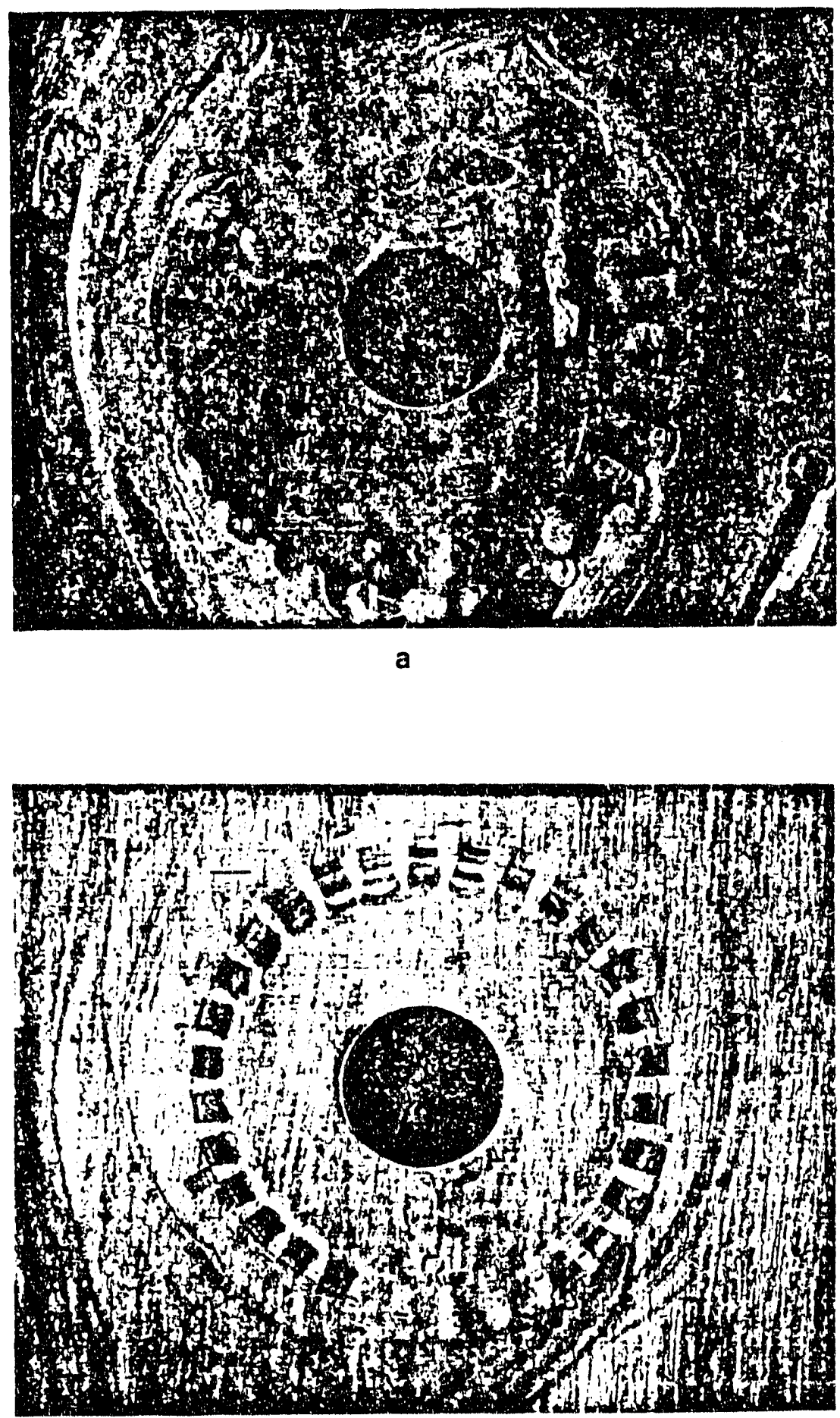

b

Fig. 15. Surfaces (front and rear) of creviced FA- 84 specimen after three-week immersion in mild acid-chloride solution. 


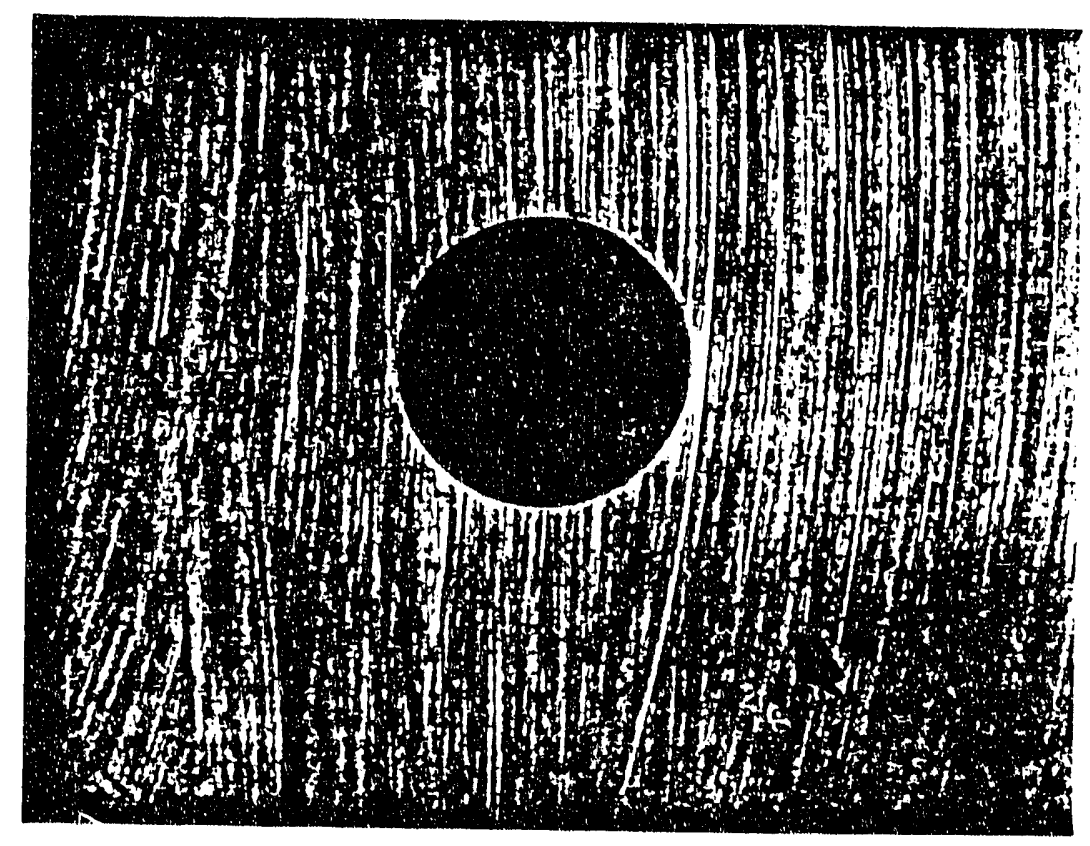

Fig. 16. Surface of creviced 304L stainless steel specimen after threeweek immersion in mild acid-chloride solution.

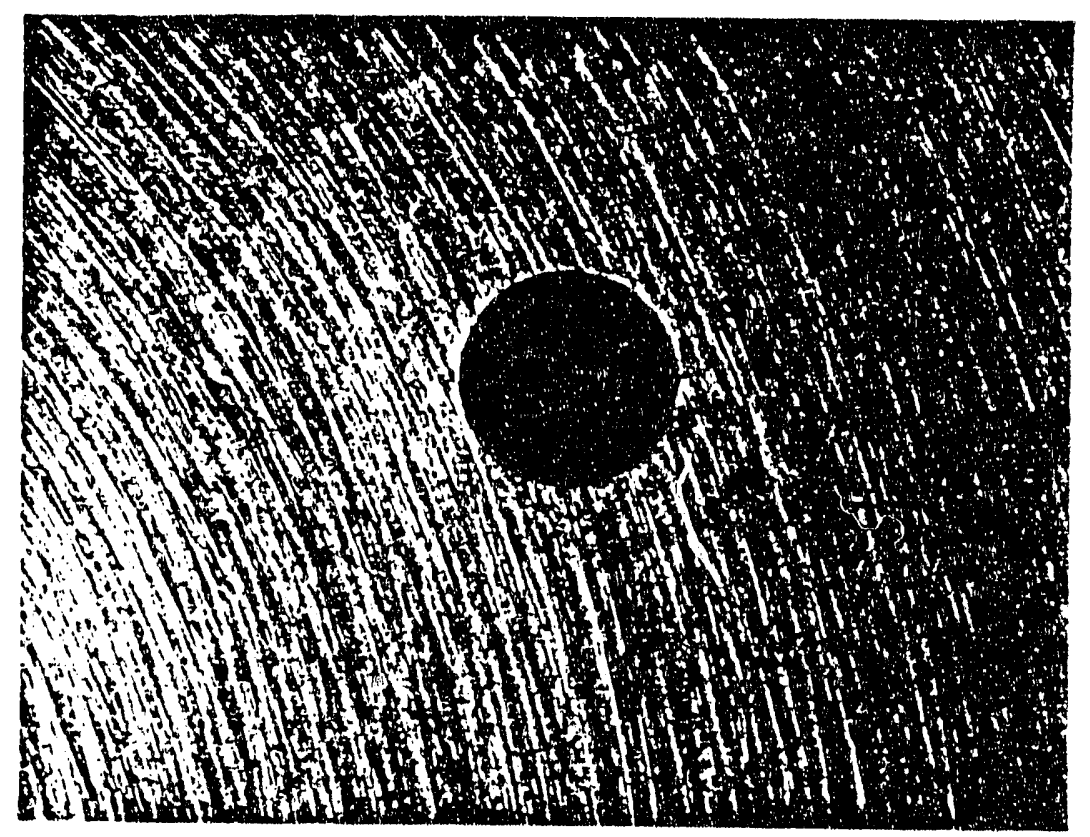

Fig. 17. Surface of creviced FAL-Mo specimen after three-weekimmersion in mild acid-chloride solution. 
Compositional Analyses of Passive Films

The passive films formed on five iron aluminides were analyzed by $\mathbf{x}$-ray photoelectron spectroscopy (XPS). The XPS method is ideal for analysis of extremelythin passive films since the depth from which compositional data are obtained is only on the order of $2 \mathrm{~nm}$. The five aluminides studied were: FA-72C (Fe-28Al-4Cr, at. \%), FA-138 (Fe-28Al-4Cr-0.5Mo), FA-139 (Fe-28Al-4Cr-1Mo), FA-140 (Fe-28Al-4Cr-2Mo), and FA-129 (Fe-28Al-5Cr-0.2C-0.5Nb). In order to develop the passive films, the specimens were immersed in the mild acid-chloride solution ( $\left.\mathrm{pH}=4\left(\mathrm{H}_{2} \mathrm{SO}_{4}\right), 200 \mathrm{ppm} \mathrm{Cl}^{-}(\mathrm{NaCl})\right)$ for 18 hours. The specimens were then removed from the solution, washed with distilled water, and dried with methanol. The XPS analyses were performed with a Perkin-Elmer PHI-5100 system using $\mathrm{Mg} \mathrm{K} \alpha$ x-radiation to produce the photoelectrons. The vacuum level during analyses was approximately $5.9 \times 10^{-9}$ torr. Compositional analyses were performed at the passive-film surfaces; depth profiling by sputtering was not performed.

The results obtained from quantitative evaluations of the XPS spectra are given in Table 7. From the XPS spectra, the metallic species in the passive films were clearly identified as the cations $\mathrm{Fe}^{3+}, \mathrm{Al}^{3+}, \mathrm{Cr}^{3+}, \mathrm{Mo}^{6+}$, and $\mathrm{Nh}^{5+}$. However, the oxygen present within the passive films could have heen in the form of either $\mathrm{O}^{2-}$ or $\mathrm{OH}^{-}-$a clear differentiation could not he determined. Thus, the passive films, depending on the alloy, consisted of mixed oxides involving $\mathrm{Fe}_{2} \mathrm{O}_{3}, \mathrm{Al}_{2} \mathrm{O}_{3}, \mathrm{Cr}_{2} \mathrm{O}_{3}, \mathrm{MoO}_{3}$ and $\mathrm{Nb}_{2} \mathrm{O}_{5}$, and/or the corresponding hydroxides $\mathrm{Fe}(\mathrm{OH})_{3}, \mathrm{Al}(\mathrm{OH})_{3}, \mathrm{Cr}(\mathrm{OH})_{3}, \mathrm{Mo}(\mathrm{OH})_{6}$ and $\mathrm{Nb}(\mathrm{OH})_{5}$. Table 7 compares the concentrations of the metallic species in the passive films with those in the bulk alloys. It is seen in all cases that the passive films contained significantly less Fe and significantly more $\mathrm{Al}$ and $\mathrm{Cr}$, and $\mathrm{Mo}$ or $\mathrm{Nb}$ (depending on the alloy) than the bulk alloys. Enrichment of the passive films with respect to $\mathrm{Al}$ and $\mathrm{Cr}$, and $\mathrm{Mo}$ or $\mathrm{Nb}$ (depending on the 
alloy) may be attributed to the preferential dissolution of Fe during the corrosion process.

To further illustrate the trends in compositional differences found in the passive films

relative to the bulk materials, the data for FA-139 is ploted as a bar graph in Figure 18.

Table 7. X-ray photoelectron spectroscopy results.

\begin{tabular}{|l|c|c|c|c|c|}
\hline \multirow{2}{*}{ Material } & \multicolumn{5}{|c|}{ Compositions: Surface (at.\%)/Bulk (at.\%) } \\
\cline { 2 - 6 } & $\mathrm{Fe}$ & $\mathrm{A}$ & $\mathrm{Cr}$ & $\mathrm{Mo}$ & $\mathrm{Nb}$ \\
\hline FA-72C (Fe-28Al-4Cr, at.\%) & $45.0 / 68$ & $43.7 / 28$ & $11.3 / 4$ & $\ldots$ & $\ldots$ \\
\hline FA-138 (Fe-28Al-4Cr-0.5 Mo) & $14.9 / 67.5$ & $65.5 / 28$ & $16.3 / 4$ & $3.2 / 0.5$ & $\ldots$ \\
\hline FA-139 (Fe28Al-4Cr-1Mo) & $15.7 / 67$ & $65.4 / 28$ & $13.0 / 4$ & $6.0 / 1$ & $\ldots$ \\
\hline FA-140 (Fe-28Al-4Cr-2Mo) & $13.5 / 66$ & $65.9 / 28$ & $12.5 / 4$ & $8.2 / 2$ & $\ldots$ \\
\hline FA129*(Fe-28Al-5Cr-0.2C-0.5Nh) & $12.3 / 66$ & $53.2 / 28$ & $28.6 / 5$ & $\ldots$ & $5.8 / 0.5$ \\
\hline
\end{tabular}

*Average of two runs.

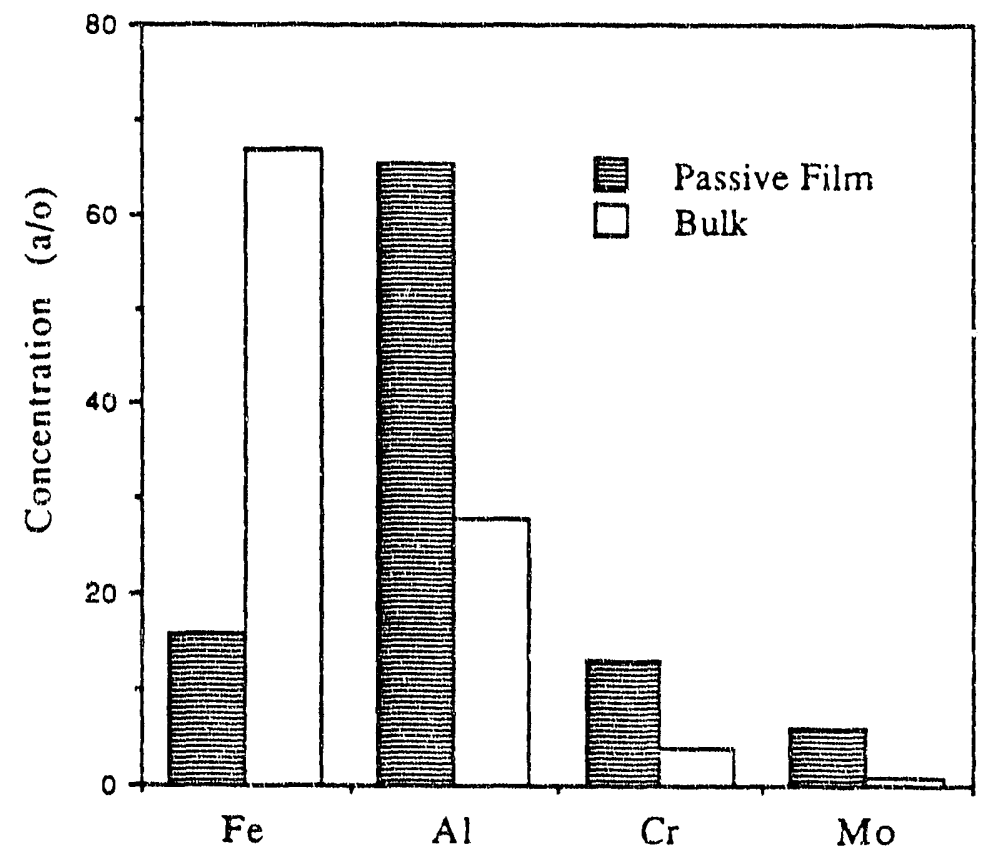

Fig. 18. Concentrations in the passive film and bulk alloy of FA-139 (Fe-28A $1-4 \mathrm{Cr}-1 \mathrm{MO}$ ) after 18 hour immersion in mild acid-chloride solution. 
With reference to the first four aluminides in Table 7, which all contained the same bulk-alloy concentrations of $\mathrm{Al}(28$ at.\%) and $\mathrm{Cr}$ ( 4 at. \%) but increasing concentrations of Mo $(0,0.5,1.0$ and 2.0 at. \%), it is seen that the increasing bulk-alloy concentration of Mo produced increasing concentrations of Mo oxide/hydroxide in the passive film. Also, the presence of Mo in the bulk alloy appeared to have increased the concentration of $\mathrm{Al}$ oxide/hydroxide in the passive film. With reference to the last aluminide in Table 7, FA129, it is seen that $\mathrm{Nb}$ oxide/hydroxide was contained in the passive film at an enriched level. Furthermore, the Al oxide/hydroxide concentration was somewhat lower and the $\mathrm{Cr}$ oxide/hydroxide concentration was considerably higher than in the passive films of the Mocontaining aluminides. Overall, then, the passive films of the Mo-containing aluminides contained mostly Al, $\mathrm{Cr}$ and Mo oxides/hydroxides ( $~ 85 \%)$; whereas the passive film on FA-129 contained mostly $\mathrm{Al}, \mathrm{Cr}$ and $\mathrm{Nb}$ oxides/hydroxides ( $88 \%)$.

Cyclic anodic polarization behaviors in the mild acid-chloride solution are shown in Figure 19 for FA-72C (Fe-28Al-4Cr, at.\%), FA-139 (Fe-28Al-4Cr-1Mo) and FA-129 (Fe$28 \mathrm{Al}-5 \mathrm{Cr}-0.2 \mathrm{C}-0.5 \mathrm{Nb})$. On comparing the curve for FA-139 (1\% Mo) with that for FA$72 \mathrm{C}(0 \% \mathrm{Mo})$, it is apparent that the Mo oxide/hydroxide enrichment within the passive film led to a significant increase in the protection potential, $E_{p}$ - - a result consistent with the observed improvements in resistance to chloride-induced localized corrosion for the Mo-containing aluminides. On the other hand, for FA-129, even though the XPS results indicated enrichment of $\mathrm{Nb}$ oxide/hydroxide in the passive film, the polarization results of Figure 19 indicated that this enrichment had no effect on $E_{p}$ and therefore no beneficial effect on resistance to chloride-induced localized corrosion. 


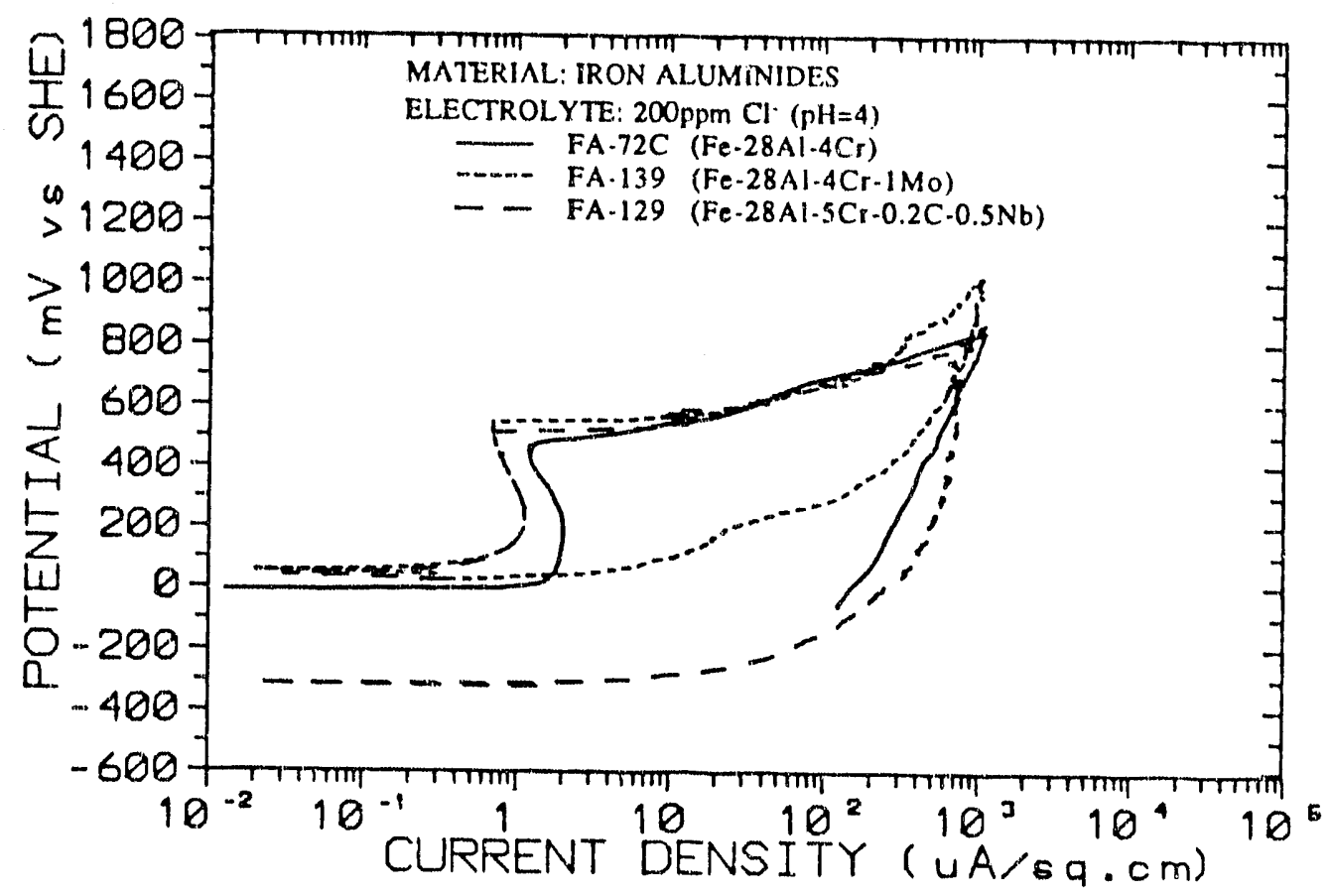

Fig. 19. Cyclic anodic polarization behaviors of FA-72C, FA-139 and FA-129 in mild acid-chloride solution. 


\section{Ductilities Under Slow-Strain-Rate Corrosion Conditions}

The tensile ductilities of $\mathrm{Fe}_{3} \mathrm{Al}$-type iron aluminides have been found to be sensitive to the moisture content of the testing environment, e.g. laboratory air. ${ }^{12,17,19}$ The mechanism responsible for this effect is believed to be hydrogen embrittlement, with the atomic hydrogen being produced by the following reaction at the iron-aluminide surface: $2 \mathrm{Al}+3 \mathrm{H}_{2} \mathrm{O} \rightarrow \mathrm{Al}_{2} \mathrm{O}_{3}+6 \mathrm{H}$. The overall reaction may be viewed as the sum of two electrochemical half-reactions: the anodic half-reaction, $2 \mathrm{Al}+3 \mathrm{H}_{2} \mathrm{O} \rightarrow \mathrm{Al}_{2} \mathrm{O}_{3}+6 \mathrm{H}^{+}+6 \mathrm{e}$; and the cathodic half-reaction, $6 \mathrm{H}^{+}+6 \mathrm{e} \rightarrow 6 \mathrm{H}$. Of practical concern is the relative severity of the hydrogen-embrittlement effect. In order to address this issue, the present study was designed to evaluate the tensile ductilities of iron aluminides under particularly severe conditions relative to possible hydrogen embrittlement: at a very-slow strain rate and in an aqueous corrosion medium. Furthermore, during testing, the electrochemical potentials of the specimens were controlled to either accelerate the production of hydrogen or to accelerate the corrosion (anodic dissolution) process. By employing these procedures, possible embrittlement by atomic hydrogen and by anodic-dissolution-based stresscorrosion cracking could be studied.

Slow-strain-rate corrosion (SSRC) tests were performed on two $\mathrm{Fe}_{3} \mathrm{Al}$-type ironaluminide alloys, FA-84 (Fe-28Al-2Cr-0.05B, at. \%) and FA-129 (Fe-28Al-5Cr-0.2C$0.5 \mathrm{Nb}$, at. \%). The SSRC tests were conducted in a mild acid-chloride solution at $\mathrm{pH}=4$ $\left(\mathrm{H}_{2} \mathrm{SO}_{4}\right)$ containing $200 \mathrm{ppm} \mathrm{Cl}^{-}(\mathrm{NaCl})$. The tests were conducted at the freely-corroding open-circuit potentials ( $E_{c o r r}$ values), at potentiostatically-controlled cathodic potentials $(-200,-1000$ and $-1500 \mathrm{mV}(\mathrm{SHE}))$, and at potentiostatically-controlled anodic potentials $(+300$ and $+500 \mathrm{mV}(\mathrm{SHE}))$. The cathodic potentials of -1000 and $-1500 \mathrm{mV}(\mathrm{SHE})$ were sufficiently negative to generate significant amounts of hydrogen uniformly over the specimen surfaces. 
The SSRC test cell consisted of a glass vessel with polyvinyl chloride top and bottom sections, containing access ports with compression fittings. Two platinum counter electrodes, one on either side of the specimen, and a Luggin probe were introduced into the cell through the compression fittings. A saturated $\mathrm{Ag} / \mathrm{AgCl}$ reference electrode was employed in monitoring the electrochemical potential of the sample. The measured potentials were converted to the standard hydrogen electrode (SHE) scale. The tensile force applied to the sample was monitored through measurement of a load-cell output, and the cross-head displacement was monitored through measurement on a multiple-turn variable resistor placed within the cross-head drive system. During a given test procedure, the applied force, cross-head displacement, and either the specimen corrosion potential (freely-corroding condition) or the external current density (constant cathodic or anodic potential) were continuously recorded.

The initial SSRC evaluations were performed with a test-specimen geometry as supplied by Oak Ridge National Laboratory (ORNL). The specimen geornetry was exactly the same as used at ORNL in their tensile-testing program (Figure 20). The specimens were annealed for 1 hour at $750^{\circ} \mathrm{C}$ (air) and oil quenched. Then the surfaces and edges were ground to a 600 -grit SiC finish. Thus, the heat-treatment oxide was removed prior to testing. The SSRC tests were conducted at a strain rate of $1.2 \times 10^{-6} / \mathrm{s}$. For comparison, the tensile testing strain rate at $\mathrm{ORNL}$ was $3.3 \times 10^{-3} / \mathrm{s}$, approximately 2700 times faster. 


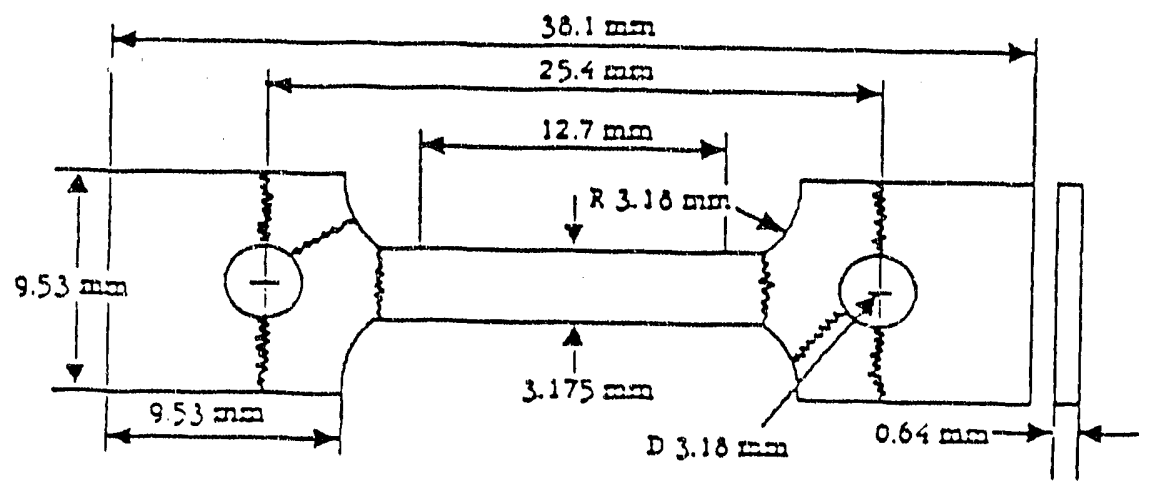

Fig. 20. Tensile specimen geometry employed at ORNL, with slowstrain-rate-corrosion fracture locations identified.

The initial testing program was plagued with difficulties. With the ORNL tensilespecimen geometry, the SSRC testing procedure produced fractures outside of the gagesection area. As indicated in Figure 20, the fractures occurred either at the pin-hole locations or where the gripping-section filet merged with the gage section. Although this mode of failure occasionally occurred during tensile testing at ORNL (strain rate $=3.3 \mathrm{x}$ $10^{-3} / \mathrm{s}$ ), it occurred 15 times in 16 tests during SSRC testing (strain rate $=1.2 \times 10^{-6} / \mathrm{s}$ ). The basic testing problem with this mode of failure was that valid \% elongation values could not be obtained under the SSRC testing procedures. Much effort and time were spent in trying to solve this problem (each SSRC test required approximately 10-60 hours). Specific actions were as follow's, in chronological order: the testing machine was evenmore carefully aligned, the specimen edges and pin-hole edges were polished to minimize stress-concentration effects, and finally, reinforcement sections were spot welded to the gripping sections to reduce the stress levels at these locations. None of these actions, involving 16 different tests, produced the desired gage-section fractures in a reproducible manner. 
As an additional action to solve the SSRC testing problem, the as-supplied ORNL tensile specimens were ground (diamond embedded grinding stone) to a series of different geometries, with the primary goal being to reduce the width of the gage section and thereby reduce the level of stress in the gripping sections. The SSRC test-specimen geometry being employed at the present time is shown in Figure 21. Its nominal gage-section width is $1.78 \mathrm{~mm}$ as compared to the original width of $3.18 \mathrm{~mm}$. Furthermore, the width of the center portion of the present SSRC test-specimen gage section was reduced by an additional $0.076 \mathrm{~mm}$. This test-specimen geometry has been found to produce valid results in that the fracture locations are generally within the gage sections.

The difficulties encountered in conducting valid SSRC tests with the as-supplied tensile-specimen geometry (Figure 20), which had worked well for the faster-strain-rate tensile tests $\left(3.3 \times 10^{-3} / \mathrm{s}\right)$ at ORNL, and the resultant necessity to reduce the gage-section width (Figure 21) for the much-slower strain-rate corrosion tests $\left(1.2 \times 10^{-6} / \mathrm{s}\right)$, and thereby to reduce the stress level in the gripping sections, suggested that the stress concentration or notch sensitivity of the iron aluminides may increase with decreasing strain rate. This possible effeci should be further siudied.

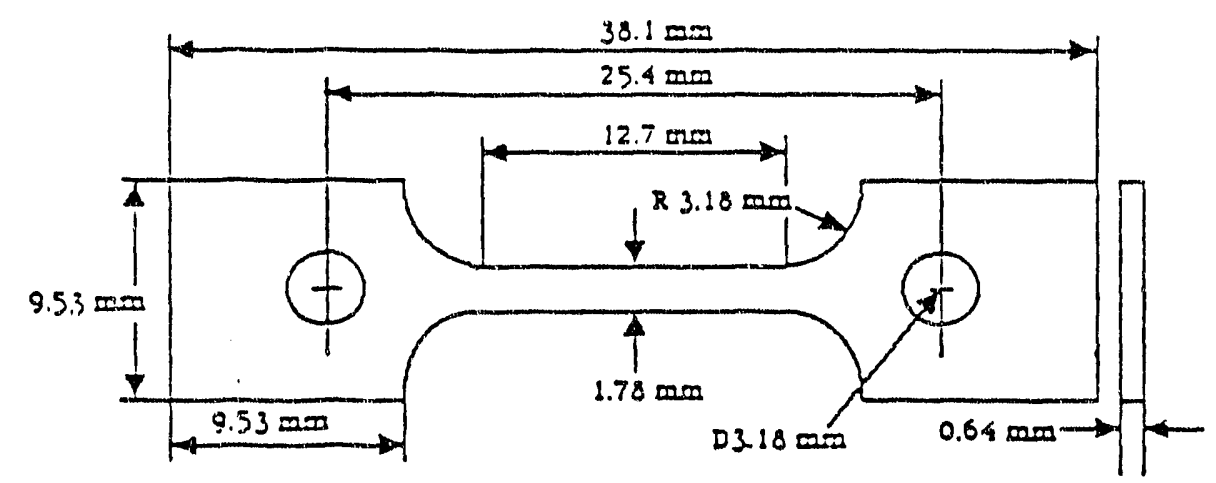

Fig. 21. Current slow-strain-rate corrosion test-specimen geometry. 
For the SSRC tests with the modified-specimen geometry, the ORNL.-supplied tensile specimens (Figure 20) were first ground to shape (Figure 21), then heat treated ( $\mathrm{h} \mathrm{h}$ at $750^{\circ} \mathrm{C}$ in air and oil quenched), and finally surface ground to a 600 -grit finish. All SSRC tests of FA- 84 were conducted on material from the same heat; similarly, all FA-129 SSRC test specimens were from the same heat. The average grain sizes for the FA- 84 and FA-129 specimens were measured and found to be $45 \mu \mathrm{m}$ (ASTM No. 6) and $21 \mu \mathrm{m}$ (ASTM No. 8), respectively. Thus, for these small test specimens with a minimum gagesection width of $1.70 \mathrm{~mm}(1,700 \mu \mathrm{m})$, the average numbers of grains across the gagesections for the FA-84 and FA-129 specimens were 38 and 81 , respectively.

The results of the SSRC tests are given in Table 8. Furthermore, as seen in Table 8, additional tests were conducted in laboratory air at the same slow strain-rate for comparison. Plots of \% plastic elongation versus potential are presented in Figures 22 and 23 for FA-84 and FA-129, respectively. For both materials under these slow-strain-rate conditions, the ductilities measured in the acid-chloride solution at the freely-corroding open-circuit potentials ( $E_{\text {corr }}$ values) were approximately the same, or greater, than those measured in laboratory air. However, at the most negative cathodic potentials ( -1000 and $-1500 \mathrm{mV}(\mathrm{SHE})$ ) and at the most positive anodic potential (+500 $\mathrm{mV}(\mathrm{SHE})$ ), the ductilities for both materials decreased significantly. 
Table 8. Slow-strain-rate $\left(1.2 \times 10^{-6} / \mathrm{s}\right)$ test results.

\begin{tabular}{|c|c|c|c|c|c|}
\hline Material & Environment & $\begin{array}{c}\text { Potential } \\
{[\mathrm{mV}(\mathrm{SHE})]}\end{array}$ & $\begin{array}{l}\text { Time to } \\
\text { Fracture } \\
\text { (h) }\end{array}$ & $\begin{array}{c}\text { Fracture } \\
\text { Stress } \\
\text { (MPa) }\end{array}$ & $\begin{array}{c}\text { Percent } \\
\text { Plastic } \\
\text { Elongation }\end{array}$ \\
\hline \multirow[t]{9}{*}{$\overline{\mathrm{FA}-84}$} & A-C Solution* & -1500 & 16 & 448 & 1.6 \\
\hline & A-C Solution & -1000 & 18 & 496 & 2.4 \\
\hline & A-C Solution & -200 & 19 & 537 & 4.7 \\
\hline & A-C Solution & $\mathrm{E}_{\text {corr }}(-50$ to +50$)$ & 42 & 758 & 10.2 \\
\hline & A-C Solution & $\mathrm{E}_{\mathrm{corr}}(-50$ to +50$)$ & 31 & 689 & 7.1 \\
\hline & A-C Solution & +300 & 37 & 551 & 7.1 \\
\hline & A-C Solution & +500 & 17 & 303 & 3.1 \\
\hline & Air & $\cdots$ & 30 & 772 & 7.2 \\
\hline & $\overline{\text { Air }}$ & -. & -- & $-\cdots$ & 5.5 \\
\hline \multirow[t]{9}{*}{$\mathrm{FA}-129$} & A.C. Solution & -1500 & 11 & 234 & 0.8 \\
\hline & A.C. Solution & -1000 & 11 & 441 & 1.6 \\
\hline & A.C. Solution & -200 & 22 & 379 & 4.0 \\
\hline & A.C. Solution & $E_{\text {corr }}(+50$ to +250$)$ & 52 & 1,068 & 6.6 \\
\hline & A.C. Solution & +300 & 42 & 696 & 7.1 \\
\hline & A.C. Solution & +300 & 38 & 620 & 6.6 \\
\hline & A.C. Solution & +500 & 8 & 220 & 0 \\
\hline & A.C. Solution & +500 & 12 & 344 & 0.8 \\
\hline & Air & -. & 31 & 675 & 6.3 \\
\hline
\end{tabular}

*Mild acid-chloride solution ( $\mathrm{pH}=4\left(\mathrm{H}_{2} \mathrm{SO}_{4}\right), 200 \mathrm{ppm} \mathrm{Cl}-(\mathrm{NaCl})$ ) 


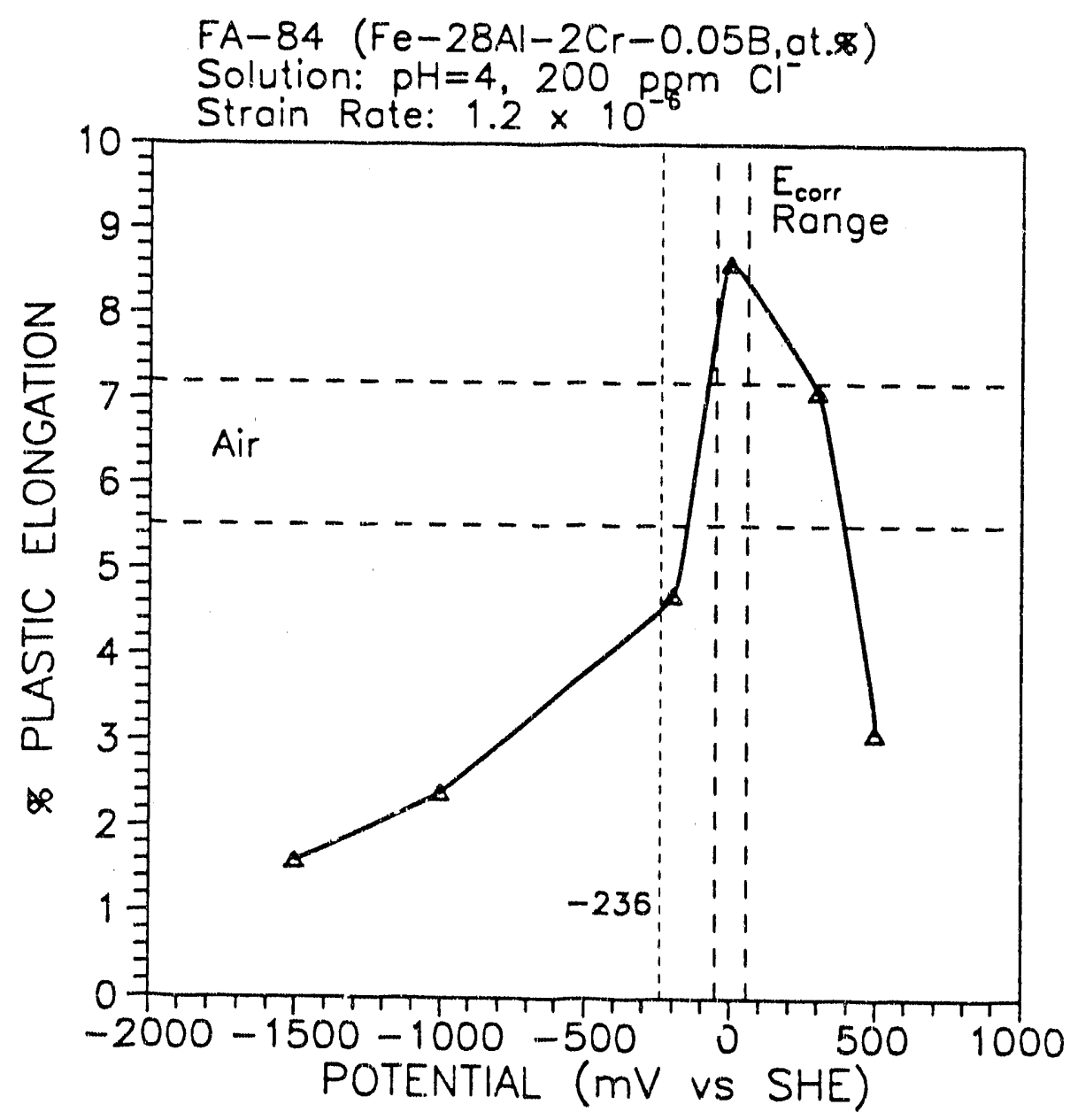

Fig. 22. Slow-strain-rate ductility versus electrochemical potential for FA-84 iron aluminide. 
FA-129 (Fe-28Al-5Cr-0.2C-0.5Nb, at.\%) Solution: $\mathrm{pH}=4,200 \mathrm{ppm} \mathrm{Cl}-$

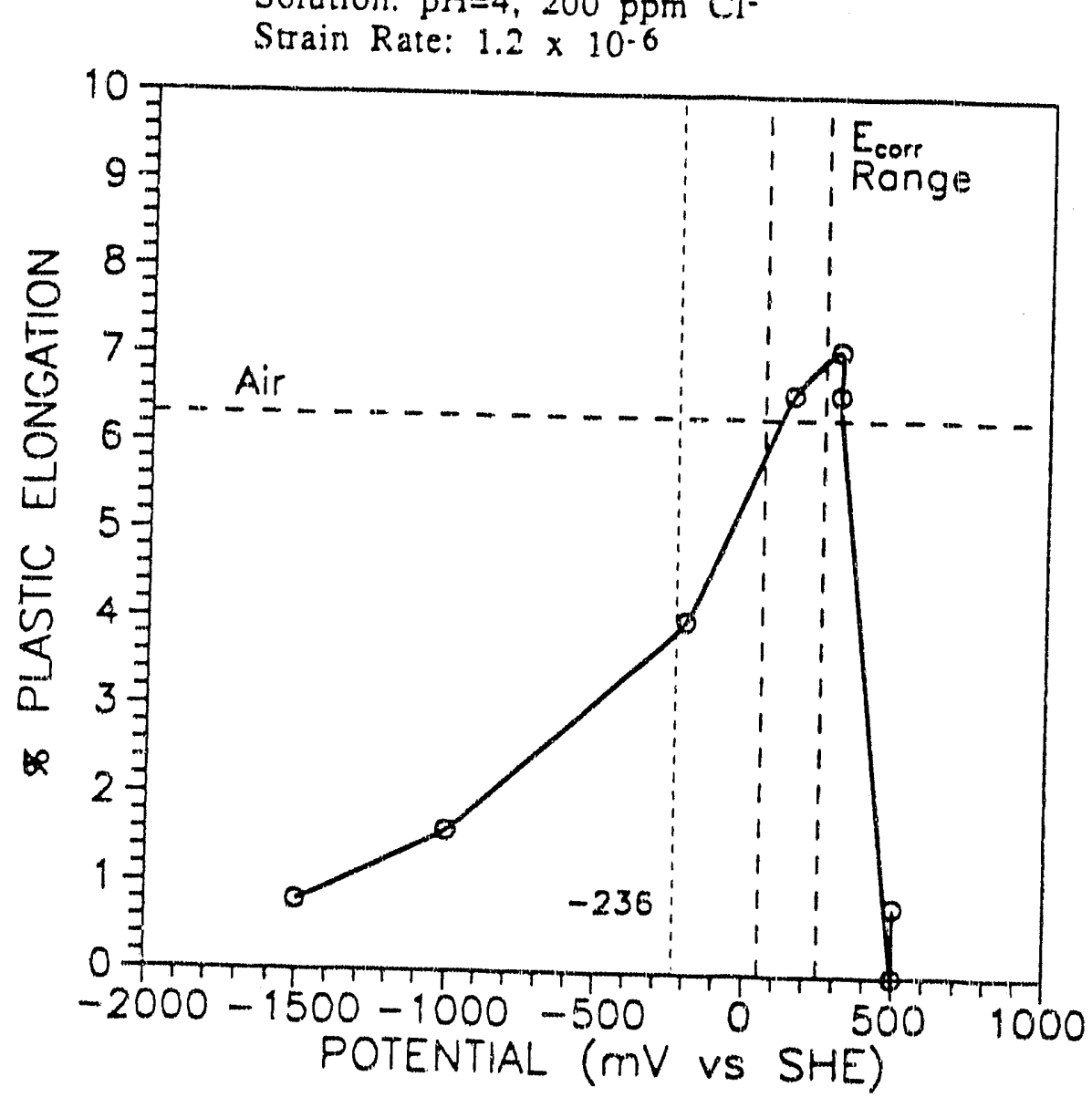

Fig. 23. Slow-strain-rate ductility versus electrochemical potential for FA-129 iron aluminide. 
Relative to interpretations of the results in Figure 22 and 23, some background information is necessary. Based on the Nernst equation for the $\mathrm{H}^{+}+\mathrm{e}=\mathrm{H}$ reaction, the equilibrium potential is given by $E_{H}^{\prime}[\mathrm{mV}(\mathrm{SHE})]=-59 \mathrm{pH}$. For the solution of the present study at $\mathrm{pH}=4, \mathrm{E}_{\mathrm{H}}^{\prime}=-236 \mathrm{mV}$ (SHE). Hydrogen production will only occur by the reaction $\mathrm{H}^{+}+\mathrm{e} \rightarrow \mathrm{H}\left(\right.$ or $\mathrm{H}_{2} \mathrm{O}+\mathrm{e} \rightarrow \mathrm{H}+\mathrm{OH}^{-}$) if the potential is below $\mathrm{E}_{\mathrm{H}}^{\prime}$, i.e. below -236 $\mathrm{mV}(\mathrm{SHE})$. At higher potentials in the oxygenated solution, only oxygen reduction occurs, $\mathrm{O}_{2}+4 \mathrm{H}^{+}+4 \mathrm{e} \rightarrow 2 \mathrm{H}_{2} \mathrm{O}$ and $\mathrm{O}_{2}+2 \mathrm{H}_{2} \mathrm{O}+4 \mathrm{e} \rightarrow 4 \mathrm{OH}^{-}$, without the production of hydrogen. As the potential decreases below $-236 \mathrm{mV}$ (SHE), the rate of uniform hydrogen production increases. Thus, in the present experiments at -1000 and $-1500 \mathrm{mV}(\mathrm{SHE})$, copious amount of uniform hydrogen-gas evolution at the specimen surfaces were cbserved. However, another aspect to this condition (i.e. uniform hydrogen production over the specimen surfaces only below - $236 \mathrm{mV}$ ) must be considered. At a given measured or controlled potential, the actual potential within occluded geometries at the surface (e.g. scratches, other flaws, etc.) will be lower than the measured or controlled potential. The magnitude of this drop in potential (an IR drop) will depend on the depth and degree-of-occlusion of the surface flaw. Thus, even though the measured or controlled potential may be above the critical value of $-236 \mathrm{mV}(\mathrm{SHE})$ for a $\mathrm{pH}$ of 4 , the actual potential within surface flaws could be below this value, and therefore hydrogen production could still occur locally within these flaws. For a given surface-flaw distribution (e.g. the 600 -grit finish employed in the present study), the probability that the critical potential will be produced within the surface flaws, and therefore the probability that hydrogen production will occur locally within the flaws, decreases as the measured or controlled potential increases. This lower probability of hydrogen production would continue to higher potentials unless a corrosion action produced a different surface-flaw distribution, e.g. pitting corrosion. Within corrosion pits formed at higher potentials, 
because of the depths and degrees of occlusion, it is possible that hydrogen production will again be accelerated locally within the pits.

Based on the prior discussion, interpretations of the ductility-versus-potential results in Figures 22 and 23 will now be presented. At potentials below - $236 \mathrm{mV}$ (SHE), both FA-84 and FA-129 suffered major decreases in ductility. Over this potential range, atomic hydrogen was being uniformly created over the specimen surfaces, with the rate of hydrogen production increasing with decreasing potential. Thus, the hydrogenembrituement mechanism is consistent with the decreasing ductilities with decreasing potentials over this potential range. In the mid-potential range (including the freelycorroding $E_{\text {corr }}$ values), hydrogen production could still have been occuring, but only locally within surface flaws. Furthermore, the rate of local wydrogen production should have been decreasing with increasing potential. Since the ductilities shown in Figures 22 and 23 progressively increased in the mid-potential range, the results suggested that the hydrogen-embrittlement mechanism was still operative, but to a decreasing extent with increasing potential. Within the potential range associated with the freely-corroding condition ( $\mathrm{E}_{\text {corr }}$ values), the ductilities were approximately the same, or greater than, the ductilities measured in air. That the ductilities were approximately the same could be explained by assuming that in air of sufficient humidity (100\% is not required), thin films of $\mathrm{H}_{2} \mathrm{O}$ were absorbed to the specimen surfaces. Then, in air, local hydrogen production occured at the specimen surfaces according to the arguments previously given. That the ductilities were approximately the same in the corrosion solution in the freely-corroding condition as in air would suggest that the same mechanism was operative (hydrogen embrittlement) and that approximately the same amount of local hydrogen was being produced in both cases. On the other hand, the freely-corroding result for FA-84 (Figure 22) indicated the ductility to be somewhat greater than in air. This particular result cannot be explained at the present time. At the highest potential in Figures 22 and 23, both FA-84 
and FA -129 suffered significant decreases in ductility. At this potential, both materials were undergoing relative high rates of corrosion. FA- 84 was undergoing both uniform and localized corrosion; whereas, FA-129 was undergoing mostly localized, pitting corrosion. Based on previous arguments, it was possible that local hydrogen production, associated with the localized corrosion, increased at this potential, and in turn, caused embrittement. On the other hand, the localized corrosion itself would have created stress-concentration sites within the apparently notch-sensitive materials (at the slow strain -rate), and this effect could have led to the decreased ductility. The relative influence of these two possible mechanisms at the highest potential are not known at the present time.

In summary, the SSRC test results indicated that the ductilities of FA-84 and FA. 129 under freely-corroding conditions were at least as high as those measured in air at the same slow strain rate. At controlled potentials progressively lower than those characteristic of the freely-corroding conditions, the ductilities continuously decreased. These results were explained as due to increased hydrogen embrittlement with decreasing potential. At the highest potential above those characteristic of the freely-corroding conditions, the ductilities again decreased. Two possible explanations were proposed to explain these results: either hydrogen production again increased, locally within corrosion pits, which led to increased hydrogen embrittlement, and/or the localized corrosion itself created stress concentration sites which led to embrittlement of the apparently notch-sensitive materials. 


\section{SUMMARY AND CONCLUSIONS}

The following section summarizes the results and conclusions of a series of aqueous-corrosion and stress-corrosion experiments on $\mathrm{Fe}_{3} \mathrm{Al}$-type iron aluminides. In all cases, the aluminide specimens were heat treated for $1 \mathrm{~h}$ at $750^{\circ} \mathrm{C}$ in air and oil quenched, then the specimen surfaces were ground to a 600 -grit SiC finish. All tests were performed at laboratory temperature $\left(\sim 25^{\circ} \mathrm{C}\right)$.

Aqueous corrosion characterizations by cyclic-anodic-polarization, polarizationresistance and immersion test methods were conducted on FA-129 (Fe-28Al-5Cr-0.2C$0.5 \mathrm{Nb}$, at.\%) and FAL-Mo (Fe-28 Al-5Cr-1Mo, at.\%), and as reference materials, on FA84 (Fe-28Al-2Cr-0.05B, at.\%) and annealed Type 304L stainless steel, in a series of acidic, basic and chloride solutions. These corrosion tests were conducted under noncrevice conditions. For each solution, the results are summarized as follows:

$1 \mathrm{~N} \mathrm{HCl}$ Acid Only active (nonpassivated) behaviors were exhibited by the aluminides and the stainless steel at all electrochemical anodic potentials. At the freely-corroding potentials, high corrosion rates were produced by all materials, with the corrosion rates decreasing in the order: FA-84, FA-129, FAL-Mo, 304L.

$1 \mathrm{NH}_{2} \mathrm{SO}_{4}$ Acid. At the freely-corroding potentials, active behaviors with high corrosion rates were exhibited by the three aluminides. The stainless steel was passivated with a very low corrosion rate. At higher potentials, the aluminides also underwent passivation. 
$1 \mathrm{~N} \mathrm{HNO}_{3}$ Acid. At the freely-corroding potentials, active behaviors were exhibited by the three aluminides, with moderate corrosion rates for FAL-Mo and FA-129, and a high corrosion rate for FA-84. The stainless steel was passivated with a very low corrosion rate. At higher potentials, the aluminides also underwent passivation.

$1 \mathrm{~N} \mathrm{NaOH}$ In this highly basic solution, at the freely-corroding potentials, all three aluminides and the stainless steel were passivated and produced very low corrosion rates. The polarization characteristics indicated no susceptibility to localized corrosion.

Chloride Solutions. In the three chloride solutions (mild acid-chloride ( $\mathrm{pH}=4$ $\left.\left(\mathrm{H}_{2} \mathrm{SO}_{4}\right), 200 \mathrm{ppm} \mathrm{Cl}^{-}(\mathrm{NaCl})\right), 3.5 \mathrm{wt} \% \mathrm{NaCl}$, and synthetic seawater $)$, at the freely-corroding potentials, all three aluminides and the stainless steel were passivated and produced low surface-average currosion rates. However, the polarization characteristics indicated susceptibility to localized corrosion, with the susceptibilities decreasing in the order: FA-84, FA-129, 304L $\approx$ FAL-Mo. During the three-week immersion tests in all three chloride solutions, localized corrosion initiated with FA-84 and FA-129, but not with 304L and FAL-Mo.

Because of the resistance to chloride-induced localized corrosion demonstrated by the FAL-Mo aluminide under non-crevice conditions, it was decided to further test this material under more-severe crevice corditions. Creviced specimens of FAL-Mo, and FA-84 and $304 \mathrm{~L}$ stainless steel as reference materials, were submitted to cyclic-anodic-polarization and immersion testing in the mild acid-chloride solution. The polarization characteristics 
indicated major detrimental crevice effects for the FA-84, but not for the $304 \mathrm{~L}$ and FALMo. In the three-week immersion tests, localized corrosion initiated at $87 \%$ of the crevice sites for FA-84, at $2 \%$ of the sites for 304L, and at none of the sites for FAL-Mo. In view of these promising results for FAL-Mo, additional crevice-corrosion experiments are now being conducted in a higher-chloride solution, $3.5 w t . \% . \mathrm{NaCl}$.

Two trends in terms of $\mathrm{Fe}_{3} \mathrm{Al}$-type aluminide chemistry are evident from the above summary of results. First, increasing the $\mathrm{Cr}$ and Mo levels are generally effective in reducing aqueous corrosion rates over the range of electrolytes investigated. That is, FA$129(5 \mathrm{Cr})$ was generally more corrosion resistant that FA-84 (2Cr), and FAL-Mo (5Cr1Mo) was generally more corrosion resistant that FA-129 (5Cr). Second, at a given $\mathrm{Cr}$ level, the addition of Mo has a major effect in improving resistance to chloride-induced localized corrosion. That is, FAL-Mo $(5 \mathrm{Cr}-1 \mathrm{Mo})$ was much more resistant to localized corrosion in chloride solutions than FA-129 (5Cr).

Because the presence of $\mathrm{Cr}$ and Mo were found to be very important for the development of passive films resistant to chloride-induced localized corrosion, the chemical compositions of passive films formed in the mild acid-chloride solution were studied by $x$ ray photoelectron spectroscopy. The oxide/hydroxide passive films were found to be depleted with respect to $\mathrm{Fe}$, and enriched with respect to $\mathrm{Al}, \mathrm{Cr}$ and $\mathrm{Mo}$.

In the last stage of this project, the ductilities of FA-84 and FA-129 were evaluated under slow-strain-rate conditions $\left(1.2 \times 10^{-6} / \mathrm{s}\right)$ in the mild acid-chloride solution and, for comparison, in laboratory air. In the acid-chloride solution, the slow-strain-rate corrosion (SSRC) tests were conducted over a range of electrochemical potentials: at freelycorroding potentials, at cathodic potentials sufficiently negative to generate hydrogen, and at anodic potentials sufficiently positive to produce pitting corrosion. The maximum ductilities (\% plastic elongation values) occured under the freely-corroding conditions for both aluminides. These ductilities were comparable to, or greater than, the ductilities 
measured in laboratory air at the same slow strain rate. At the hydrogen-producing cathodic potentials, the ductilities decreased significantly -- an effect consistent with hydrogen embrittement. At the highest anodic potential, where pitting corrosion was occuring, the ductilities again decreased significantly. This embrittlement was interpreted as being caused by stress-concentration effects associated with the corrosion pits and/or by the production of hydrogen within the corrosion-pit occluded geometries. 


\section{REFERENCES}

1. V.K. Sikka, C.G. McKamey, C. R. Howell, and R.H. Baldwin, "Fabrication and Mechanical Properties of $\mathrm{Fe}_{3} \mathrm{~A} 1$ - Based Iron Aluminides, " U.S. DOE Fossil Energy AR \&TD Materials Program, Oak Ridge National Labortory, ORNL/TM. 11465, March, 1990.

2. C.G. McKamey, "Development of Iron Aluminides," Proceedings of the Fourth Annual Conference on Fossil Energy Materials, Fossil Energy AR \& TD Materials Program, Oak Ridge National Laboratory, Oak Ridge, TN, CONF - 900546, ORNL/FMP-90/1, pp.197-206, August, 1990.

3. D.J. Alexander, J.H. DeVan and V.K. Sikka, "Moisture-Induced Embrittlement of $\mathrm{Fe} 3 \mathrm{Al}$, "Proceedings of the Fourth Annual Conference on Fossil Energy Materials, Fossil Energy AR \& TD Materials Program, Oak Ridge National Laboratory, Oak Ridge, TN, CONF -900546, ORNL/FMP-90/1, pp. 215-218, August 1990.

4. V.K. Sikka, "Meling of Iron-Aluminide Alloys,"Proceedings for the Fourth Annual Conference on Fossil Energy-Materials, Fossil Energy AR \& TD Materials Program, Oak Ridge National Laboratory, Oak Ridge, TN., CONF-900546, ORNL/FMP90/1, pp. 219-230, August 1990.

$5 \quad$ Mechanical Properties of Fe 3 Al Alloys," Proceedings of the Fourth Annual Conference on Fossil Energy Materials, Fossil Energy AR \& TD Materials Program, Oak Ridge National Laboratory, Oak Ridge, TN, CONF-900546, ORNL/FMP-90/1, pp.231-239, August 1990.

6. W.H. Lee and R.Y. Lin, "Molten Salt-Induced Hot Corrosion of Iron Aluminides," Proceedings of the Fourth Annual Conference on Fossil Energy Materials, FossilEnergy AR \& TD Materials Program, Oak Ridge National Laboratory, Oak Ridge, TN, CONF-900546, ORNL/FMP-90/1, pp.475-486, August, 1990.

7. C.G. McKamey and P.J.Maziasz, "Development of Iron Aluminides," Proceedings of the Fifth Annual Conference on Fossil Energy Materials, Fossil Energy AR\&TD Materials Program, Oak Ridge National Laboratory, Oak Ridge, TN, Conf9105184, ORNL/FMP-91/1, pp.175-185, Sept., 1991.

8. H.D. Brody and L.L. Rishel, "Melting, Casting, and Solidification Behavior of Iron Aluminides," Proceedings of the Fifth Annual Conference on Fossil Energy Materials, Fossil Energy AR \& TD Materials Program, Oak Ridge National Laboratory, Oak Ridge, TN, Conf-9105184, ORNL/FMP-91/1, pp.187-196, Sept., 1991.

9. V.K. Sikkâ, R.H. Baldwin, K.S. Blakely, E.C. Hatfield, C.R. Howell, and C.G. McKamey, "Preparation and Fabrication of Iron Alurninides," Proceedings of the Fifth Annual Conference on Fossil Energy Materials, Fossil Energy AR \& TD Materials Program, Oak Ridge National Laboratory, Oak Ridge, TN, Conf-9105184, ORNL/FMP-91/1, pp. 197-207, Sept. 1991. 
10. R.N. Wright and J.R. Kilgore, "The Influence of Thermomechanical Processing on the Structure and Properties of Fe3Al," Proceedings of the Fifth Annual Conference on Fossil Energy Materials, Fossil Energy AR \& TD Materials Program, Oak Ridge National Laboratory, Oak Ridge, TN, Conf-9105184, ORNL/FMP-91/1, pp.219228, Sept. 1991.

11 D.J. Alexander and V.K. Sikka, "Fracture Behavior of Fe 3 Al Alloy FA-129," Proceedings of the Fifth Annual Conference on Fossil Energy Materials, Fossil Energy AR \& TD Materials Program, Oak Ridge National Laboratory, Oak Ridge, TN, Conf-9105184, ORNL/FMP-91/1, pp.239-248, Sept. 1991.

12. A. Castagna and N.S. Stoloff, "Moisture-Induced Embrittlement of Iron Aluminides," Proceedings of the Fifth Annual Conference on Fossil Energy Materials, Fossil Energy AR \& TD Materials Program, Oak Ridge National Laboratory, Oak Ridge, TN, Conf-9105184, ORNL/FMP-91/1, pp.249-259, Sept. 1991.

13. J.H. DeVan, "Environmental Effects on Iron Aluminides," Proceedings of the Fifth Annual Conference on Fossil Energy Materials, Fossil Energy AR \& TD Materials Program, Oak Ridge National Laboratory, Oak Ridge, TN, Conf-9105184, ORNL/FMP-91/1, pp.261-270, Sept. 1991.

14. R.A. Buchanan and J.G. Kim, "Aqueous Corrosion Characteristics and CorrosionRelated Cracking Susceptibilities of Fe 3 Al-Type Iron Aluminides," Department of Energy, Fossil Energy Advanced Research and Technology Development Materials Program, Report ORNL/Sub/88-07685CT92/01, National Technical Information Service, Springfield, VA, April 1991.

15. R.A. Buchanan and J.G. Kim, "Aqueous Corrosion and Stress Corrosion Cracking of Iron Aluminides," Proceedings of the Fourth Annual Conference on Fossil Energy Materials, Fossil Energy AR \& TD Materials Program, Oak Ridge National Laboratory, Oak Ridge, TN, CONF-900546, ORNL/FMP-90/1, pp.383-90, Augus* 1990.

16. R.A. Buchanan and J.G. Kim, "Ductilities of Iron Aluminides Under Slow-StrainRate Corrosion Conditions With and Without Hydrogen Charging," Proceedings of the Fifth Annual Conference on Fossil Energy Materials, Fossil Energy AR \& TD Materials Program, Oak Ridge National Laboratory, Oak Ridge, TN, Conf-9105184, ORNL/FMP-91/1, pp.271-279, Sept. 1991.

17. C.T. Liu, E.H. Lee, and C.G. McKamey, Scripta Metall. 23 (1989) 875.

18. C.T. Liu, C.G. McKamey, and E.H. Lee, Scripta Metall.24 (1990) 385.

19. C.T. Liu and C.G. McKamey, pp.133-151 in High Temperature Aluminides and Intermetallics, ed. S.H. Whang, C.T. Liu, D.P. Pope, and J.O. Stiegler, The Minerals, Metals and Materials Society, 1990. 
APPENDIX: DISTRIBUTION LIST

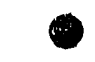

-

-

궁

0

li 
AIR PRODUCTS AND CHEMICALS

P.O. Box 538

Alentown, PA 18105

S. W. Dean

S. C. Weiner

ALBERTA RESEARCH COUNCIL

Oil Sands Research Department

P.O. Box 8330

Postal Station F

Edmonton, Alberta

Canada T6H5X2

L. G. S. Gray

ALLISON GAS TURBINE DIVISION

P.O. Box 420

Indianapolis, IN 46206-0420

P. Khandelwal (Speed Code W-5)

R. A. Wenglarz (Speed Code W-16)

ARGONNE NATIONAL IABORATORY

9700 S. Cass Avenue

Asgonne, 1L. 60439

K. Natesan

ARGONNE NATIONAL LABORATORY-WEST

P.O. BOX 2528

Idaho Falls, ID 83403.2528

S. P. Henslec

AVCO RESEARCH LABORATORY

2385 Revere Beach Parkway

Evercli, MA 02149

R. J. Pollina

BABCOCK \& W'ILCOX

1562 Becson St.

Alliance, OH $\$ 4601$

T. I. Johnson

T. Modrak

BABCOCK \& WILCOX

Domestic Fossil Opcrations

20 South Van Buren Avenue

Barberton, OH 44023

M. Gold

BATTELLE-COLUMBUS LABORATORIES

505 King Avenue

Columbus, OH 43201

1. G. Wright

BRITISH COAL CORPORATION

Coal Research Establishment

Stoke Orchard, Cheltenham

Glochester, England GL52 4RZ

M. Arnold

C. Bower

A. Twigg

\section{BRITISH GAS CORPORATION}

Westfield Development Centre

Cardenden, Fife

Scotland KY5OHP

J. E. Scoll

BROOKHAVEN NATIONAL LABORATORY

Departinent of Applied Science

Upion, Long Island, NY 11973

T. E. O'Hare

CANADA CENTER FOR MINERAL \& ENERGY TECHNOLOGY

568 Booth Street

Ottawa, Ontario

Canada KIA OG1

R. Winston Revic

Mahi Sahoo

CONSOLIDATION COAL COMPANY

4000 Brownsville Road

Library, PA 15129

S. Harding

ELECTRIC POWER RESEARCH INSTTTUTE

P.O. Box 10412

3412 Hillview Avenue

Palo Alıo, CA 94303

W. T. Bakker

J. Stringer

R. H. Wolk

\section{EUROPEAN COMMUNITIES JOINT RESEARCIY} CENTRE

Petten Establishment

P.O. Box 2

1755 ZG Petten

The Netherlands

M. Van de Voorde

FLUIDIZED BED TECHNOLOGYES

P. O. Box 4469

Chattanooga, TN 37405

R. Q. Vincent

\section{FOSTER WHEELER DEVELOPMENT}

CORPORATION

Materials Technology Department

John Blizard Research Center

12 Peach Tree Hill Road

Livingston, NJ 07039

J. L. Blough

GAS RESEARCH INSTITUTE

8600 West Bryn Mawt Avenue

Chicago, IL 60631

H. S. Meyer 
GENERAL ELECTRIC COMPANY

1 River Road, Bldg. 55, Room 115

Scheneclady, NY 12345

R. W. Haskell

\section{IDAHO NATIONAL ENGINEERING}

LABORATORY

P. O. Box 1625

Idaho Falls, ID 83415

D. W. Keefer

\section{IOWA STATE UNIVERSITY}

Materials Science and

Engineering Department

Ames, IA 50001

110 Engineering Annex

K. M. Vedula

LAWRENCE LIVERMORE LABORATORY

P.O. Box 808, L.325

Livermore, CA 94550

W. A. Stecle

\section{MOBIL RESEARCH \& DEVELOPMENT CORPORATION}

P. O. Box 1026

Princeton, NJ 08.540

R. C. Searles

NATIONAL MATERIALS ADVISORY BOARD National Research Council

2101 Constitution Avenue

Washington, DC 20418

K. M. Zwilsky

NEW ENERGY AND INDUSTRIAL TECHNOLOGY DEVELOPMENT ORGANIZATION

Sunshine $60 \mathrm{Bldg}$.

P.O. Box 1151

1-1, Higashi-lkebukuro 3-chrome

Toshima-Ku, Tokyo, 170

Japan

H. Narita

S. Ueda

OAK RIDGE NATIONAL LABORATORY'

P.O. Box 2008

Oak Ridge, TN

P. T. Carlson

N. C. Cole

J. H. DeVan

R. R. Judkins

R. A Lauson (8 copics)

RISOE NATIONAL LABORATORY

P.O. Box 49

DK-4000

Roskilde, Denmark

Aksel Olsen
SHELL DEVELOPMENT COMPANY

P. O. Box 1380

Houston, TX 77251-1380

L. W. R. Dicks

SOUTHWEST RESEARCH INSTTTUTE

6620 Culebra Road

P.O. Drawer 28510

San Antonio, TX 78284

F. F. Lyle, Jr.

TENNESSEE VALLEY AUTHORITY

Energy' Demonstration \& Technology

MR 2N58A

Chattanooga, TN 37402-2801

C. M. Huang

TENNESSEE VALLEY AUTHORITY

1101 Market Street

3A Missionary Ridge

Chattanooga, TN 37402-2801

A. M. Manaker

TEXAS EASTERN TRANSMISSION

CORPORATION

P.O. Box 2521

Houston, TX 77252

D. H. France

THE MATER ALS PROPERTIES COUNCIL, INC.

United Engineering Center

345 E. Forty-Seventh Street

New York, NY 10017

M. Prager

THE TORRINGTON COMPANY

Advanced Technology Center

59 Field Streel

Torrington, CT 06790

W. J. Chmura

UNIVERSAL ENERGY SYSTEMS, INC.

4401 Dayton-Zenia Road

Dayton, $\mathrm{OH} 45432$

V. Srinivasan

UNIVERSITY OF CALIFORNIA AT BERKELEY

Department of Materials Science

and Mineral Engineering

Berkeley, CA 94720

E. R. Parker

UNIVERSITY OF TENNESSEE AT KNOXVILLE

Materials Science and Engineering

Department

Knoxville, TN 37996

R. A. Buchana

C. D. Lundin 
UNIVERSITY OF TENNESSEE SPACE INSTITUTE

Tullahoma, TN 37388

J. W. Muehlhauser

\section{WESTERN RESEARCH INSTTTUTE}

$365 \mathrm{~N}$. 9th Street

P.O. Box 3395

University Station

Laramic, WY 82071

V. K. Sethi

WESTINGHOUSE ELECTRIC CORPORATION

Research and Development Center

1310 Bculah Road

Pittsburgh, PA 15235

S. C. Singhal

WESTINGHOUSE HANFORD COMPANY

P.O. Box 1970, W/A-65

Richland, WA 99352

R. N. Johnson

DOE

DOE OAK RIDGE FIELD OFFICE

P. O. Box 2001

Oak Ridge, TN 37831

Assistani Manager for Energy Research and

Development

DOE

DOE OAK RIDGE FIELD OFFICE

P. O. Box 2008

Building 4500N, MS 6269

Oak Ridgc, TN 378.31

E. E. Hoffman

DOE

OFFICE OF BASIC ENERGY SCIENCES

Materials Sciences Division

ER-131, GTN

Washington, DC 20545

J. B. Darby

DOE

OFFICE OF CONSERVATION AND

RENEWABLE ENERGY

CE-12, Forrestal Building

Washington, DC 20545

J. J. Eberhardt

DOE

OFFICE OF FOSSIL ENERGY

Washington, DC 20545

J. P. Carr (FE-14)
DOE

MORGANTOWN ENEP.GY TECHNOLOGY' CENTER

P.O. Box 880

Morgantown, WV 26505

R. A. Bajura

R. C. Bedick

D. C. Cicero

F. W. Crouse, Jr.

N. T. Holcombe

W. J. Huber

J. E. Notestein

J. S. Wilson

DOE

PITTSBURGH ENERGY TECHNOLOGY CENTER

P.O. Box 10940

Pitlsburgh, PA 15236

A. H. Balduin

G. V. McGurl

R. Santore

T. M. Torkos 

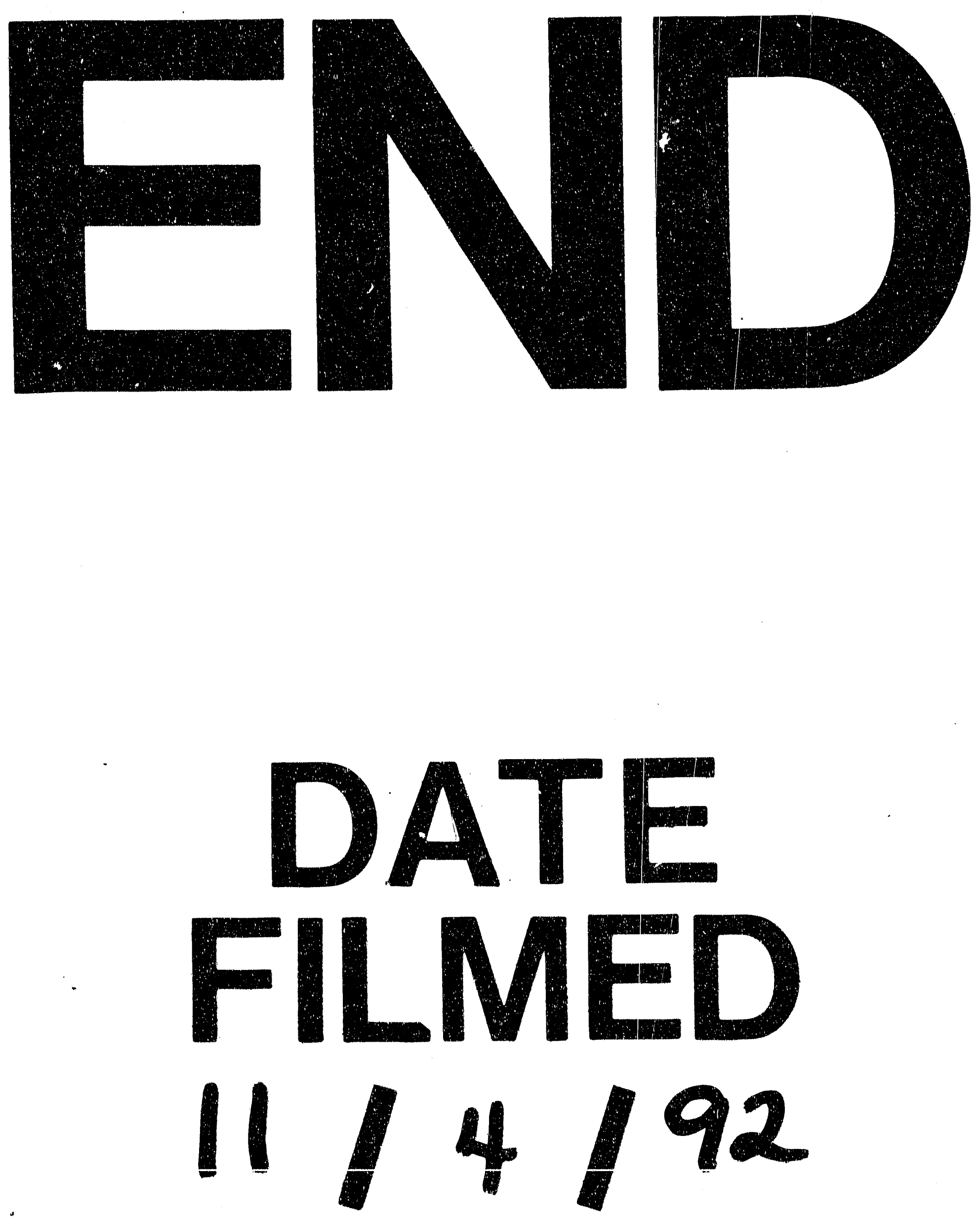
